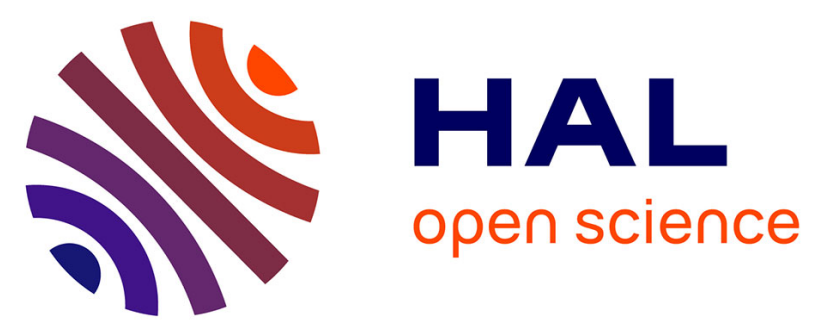

\title{
Electron-Deficient Dihydroindaceno-Dithiophene Regioisomers for n-Type Organic Field-Effect Transistors
} Jean-David Peltier, Benoît Heinrich, Bertrand Donnio, Joëlle Rault-Berthelot, Emmanuel Jacques, Cyril Poriel

\section{- To cite this version:}

Jean-David Peltier, Benoît Heinrich, Bertrand Donnio, Joëlle Rault-Berthelot, Emmanuel Jacques, et al.. Electron-Deficient Dihydroindaceno-Dithiophene Regioisomers for n-Type Organic FieldEffect Transistors. ACS Applied Materials \& Interfaces, 2017, 9 (9), pp.8219-8232. 10.1021/acsami.6b16333 . hal-01501263

HAL Id: hal-01501263

https://hal-univ-rennes1.archives-ouvertes.fr/hal-01501263

Submitted on 4 Jul 2017

HAL is a multi-disciplinary open access archive for the deposit and dissemination of scientific research documents, whether they are published or not. The documents may come from teaching and research institutions in France or abroad, or from public or private research centers.
L'archive ouverte pluridisciplinaire HAL, est destinée au dépôt et à la diffusion de documents scientifiques de niveau recherche, publiés ou non, émanant des établissements d'enseignement et de recherche français ou étrangers, des laboratoires publics ou privés. 
Electron Deficient Dihydroindaceno-Dithiophene Regioisomers for n-Type

\title{
Organic Field-Effect Transistors
}

Jean-David Peltier, ${ }^{\mathrm{a}}$ Benoît Heinrich, ${ }^{\mathrm{c}}$ Bertrand Donnio, ${ }^{\mathrm{c}}$ Joëlle Rault-Berthelot, ${ }^{\mathrm{a}^{*}}$ Emmanuel Jacques $^{\mathrm{b}^{*}}$ Cyril Poriel ${ }^{\mathrm{a}^{*}}$

${ }^{a}$ UMR CNRS 6226-Institut des Sciences Chimiques de Rennes- Équipe Matière Condensée et Systèmes Électroactifs, Bat 10C, Campus de Beaulieu - 35042 Rennes cedex France

${ }^{\mathrm{b}}$ UMR CNRS 6164-Institut d'Électronique et des Télécommunications de Rennes- Département Microélectronique \& Microcapteurs, Bât.11B, Université Rennes 1, Campus de Beaulieu 35042 Rennes Cedex, France

${ }^{c}$ Institut de Physique et Chimie des Matériaux de Strasbourg (IPCMS), UMR 7504, CNRSUniversité de Strasbourg, 23 rue du Loess, BP 43, 67034 Strasbourg Cedex 2, France

joelle.rault-berthelot@univ-rennes1.fr, emmanuel.jacques@univ-rennes1.fr, cyril.poriel@univrennes1.fr

Keywords: Organic Field-Effect Transistor, Organic Semi-Conductors, Dihydroindaceno-Dithiophene, FET mobility, flexible electronics, metal-semiconductor interface

\begin{abstract}
In this work, we wish to report the first member of a new family of organic semi-conductors constructed on a meta dihydroindacenodithiophene core, that is 2,2'-(2,8-dihexyl-4,6-dihydro-s-indaceno[1,2-b:7,6- $b$ ]dithiophene-4,6-diylidene)dimalononitrile (called meta-IDT $\left.\left(=\mathbf{C}(\mathbf{C N})_{2}\right)_{2}\right)$. The properties of this molecule have been studied in detail through a structure properties relationship study with its regioisomer, that is 2,2'-(2,7-dihexyl-4,9-dihydro-s-indaceno[1,2- $b$ :5,6b' dithiophene-4,9-diylidene)dimalononitrile (para-IDT $\left.\left(=\mathbf{C}(\mathbf{C N})_{2}\right)_{2}\right)$ (see isomers structures in blue in Chart 2). The influence of the bridge functionalization has also been investigated by comparison with their diketone analogues meta-IDT $(=\mathbf{O})_{2}$ and para-IDT $(=\mathbf{O})_{2}$. This study sheds light on the impact of regioisomerism on the electronic properties at the molecular level (electrochemistry, absorption spectroscopy, molecular modelling) and also on the supramolecular arrangement (SWAXS), and finally on the OFET performances and stabilities. The significant effect of self-assembled monolayers of 4-(dimethylamino) benzenethiol (DABT) grafted on the gold drain and source electrodes or of the use of flexible substrate (polyethylene naphtalate: PEN) instead of glass on the OFET performances and stabilities are also reported. In the light of these results (maximum mobility reaching $7.1 \times 10^{-2} \mathrm{~cm}^{2} \mathrm{~V}^{-1} \mathrm{~cm}^{-1}$, high $\mathrm{Id}_{\text {on }} / \mathrm{Id}_{\text {off }}$ of $2.3 \times 10^{7}$ and
\end{abstract}


subthreshold swing of $1.2 \mathrm{~V} / \mathrm{dec}$ ), we believe that the present OFETs can be further used to construct electronic circuits.

\section{Introduction}

The exponential development of organic electronic leads to an always growing demand of new, highly efficient organic semiconductors (OSCs) adapted to their use in specific devices ${ }^{1}$ including organic light-emitting diodes (OLED) based on fluorescent emitting materials, ${ }^{2-8}$ or based on phosphorescent materials, ${ }^{9-19}$ organic field-effect transistor $(\text { OFET })^{20-24}$ or organic photovoltaic (OPV). ${ }^{1,25}$ Historically, in the field of OFETs, the design of p-type materials (hole-transporting) such as pentacene, ${ }^{26}$ oligothiophene ${ }^{27}$ or bridged oligoarylene ${ }^{28-29}$ derivatives have received most of the attention. For instance, air-stable p-type OFET with hole mobility $\left(\mu_{\mathrm{h}}\right)$ reaching $5-10 \mathrm{~cm}^{2} \mathrm{~V}^{-}$ ${ }^{1} \mathrm{~s}^{-1}$ have been reported in literature for (triisopropylsilylethynyl)pentacene $(\mathbf{1}),{ }^{30}$ alkylated dinaphtothienothiophene $(2)^{31}$ or benzothienobenzodithiophene $(3)^{32}$ and $\mu_{\mathrm{h}}$ even greater than 40 $\mathrm{cm}^{2} \mathrm{~V}^{-1} \mathrm{~s}^{-1}$ for 2,7-dioctyl-[1]benzothieno[3,2-b][1]benzothiophene(4), ${ }^{33}$ (see 1-4 structures in Chart 1). However, the development of $\mathrm{p}-\mathrm{n}$ junctions, such as ambipolar transistors and complementary logic circuits with low power consumption and high operating level has extended the demand for efficient n-type (electron-conducting) OSCs with performances comparable to those of p-type OSC. Nevertheless, and despite the numerous breakthroughs in the last ten years, the best n-channel materials are not as good as the best p-channel materials mentioned above. Most of the n-type OFETs present electron mobility $\left(\mu_{\mathrm{e}}\right)$ performances lower than $1 \mathrm{~cm}^{2} \mathrm{~V}^{-1} \mathrm{~s}^{-1}$. To the best of our knowledge, the best n-type OFET performances reported to date use N-fluoro-alkyl functionalized dicyano-perylene diimides $5^{34} \pi$-expanded quinoidal terthiophene $\mathbf{6}^{35}$ or naphthalene diimides fused with 2-(1,3-dithiol-2-ylidene)malononitrile derivative $7,{ }^{36}$ with $\mu_{\mathrm{e}}$ of 1.3, 3.0 and $3.5 \mathrm{~cm}^{2} \mathrm{~V}^{-1} \mathrm{~s}^{-1}$, respectively (see structures 5-7 in Chart 1). 

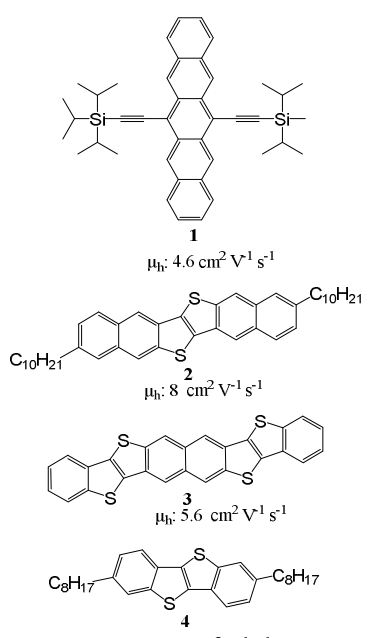

$\mu_{\mathrm{h}}: 43 \mathrm{~cm}^{2} \mathrm{~V}^{-1} \mathrm{~s}^{-1}$

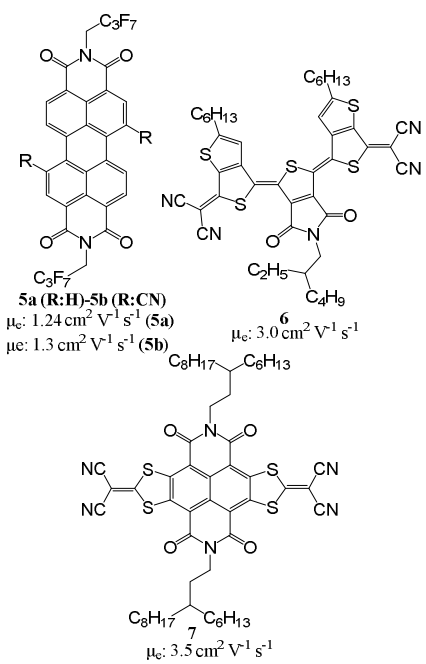

Chart 1. Molecular structures of the high efficiency hole-transporting OSCs (1-4) ${ }^{30-33}$ (left) and electron-transporting $\operatorname{OSCs}(5-7)^{34-36}$ (right).

In the field of organic electronic, there are two main ways to increase the efficiency/stability of the device. The first is driven by molecular chemists and deals with the design of highly efficient OSCs perfectly fitting the necessary requirements of a specified device, this is called molecular engineering. The second is driven by physicists and electronicians and deals, no more with molecular engineering, but this time with device engineering. These 2 approaches have led to the fantastic development of organic electronics for the last twenty years and continue to be the driving force of the field. In the present work, these two approaches have been investigated.

To produce OSCs fitting the requirements of organic devices, the most developed strategy of molecular engineering consists in the judicious incorporation of donor and/or acceptor fragments to a common molecular $\pi$-conjugated core. Among the molecular features that allow the modulation of OSC properties, regioisomerism can have remarkable consequences on the properties of the molecules. ${ }^{6,21,37-38}$ A simple structural modification can indeed drastically influence the oxidation potentials, ${ }^{3,6,11,39-41}$ the fluorescence properties, ${ }^{3-5}$ the intermolecular $\pi-\pi$ stacking, ${ }^{42-43}$ which determines the magnitude of the charge-transfer integral and thus the charge transport in OSC devices. An interesting example of such architecture modification inducing strong changes both in the film morphology and OFETs performances has been reported for $2 \mathrm{D} \pi$ expanded quinoidal terthiophenes. ${ }^{35}$ Indeed, OSC 6 (see structure in Chart 1) in which the two sulphur atoms of the thieno-thiophene units point outwards presents an electron mobility of 3.0 $\mathrm{cm}^{2} \mathrm{~V}^{-1} \mathrm{~s}^{-1}$ nearly 7 times higher than that of its regioisomer with the sulphur atoms pointing toward the centre of the molecule $\left(\mu_{\mathrm{e}}: 0.44 \mathrm{~cm}^{2} \mathrm{~V}^{-1} \mathrm{~s}^{-1}\right)$. Even larger changes of charge transport performances as well as film morphologies were observed for two fluorenone-di-(octylthiophene) regioisomers with different position of the side alkyl tails on the thiophene ring, in relation with 
the modified mesomorphic properties. ${ }^{44}$ It should moreover be mentioned that similar effects were also reported in the field of OLEDs with dihydroindenofluorene regioisomers (constructed either on para or meta bridged terphenyl fragments). ${ }^{6,}{ }^{21}$ Finally, a last but not least consideration is linked to the fact that most of the OSCs reported in literature for organic electronics possess a linear shape and only very recently, Müllen group has reported n-type OSC with angular-shaped structure $^{45}$ leading to electron mobilities reaching $0.01 \mathrm{~cm}^{2} \mathrm{~V}^{-1} \mathrm{~s}^{-1}$. Similarly, Okamoto and Takeya groups have reported V-shaped OSCs with hole mobilities reaching a very high mobility of $4 \mathrm{~cm}^{2}$ $\mathrm{V}^{-1} \mathrm{~s}^{-1} \cdot{ }^{46}$ A supplementary factor, the 'shape', seems then to play a key role on the packing in the solid state with a positive influence on the charge mobility. Exploiting regioisomerism therefore turns out to be an interesting strategy, since $\pi$-conjugated cores developed to date in literature for n-type OFET show a rather restricted diversity. ${ }^{47-48}$

Regarding the device engineering, in 2009, Kitamura et al have demonstrated that electrode functionalization with some benzenethiol derivatives such as 4-(dimethylamino)benzenethiol (DABT) could have a high impact on electrical performance due to a better OSC organization on drain and source electrodes. ${ }^{49}$ This improvement can be explained by (i) the electron donating nature of DABT, (ii) the better morphology of the OSC thin film at the Au-DABT/OSC interface compare to bare $\mathrm{Au} / \mathrm{OSC}$ and (iii) the reduction of the electron-injection barrier height by shifting the Fermi level of $\mathrm{Au}^{49}$
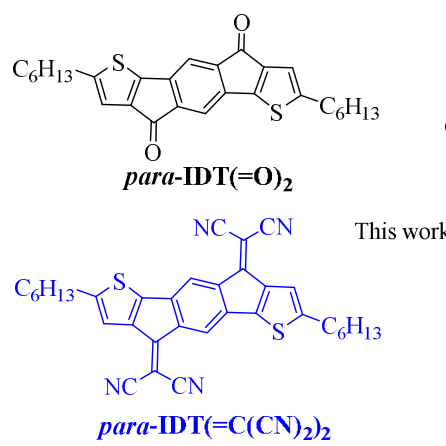

Indacenodithiophene derivatives

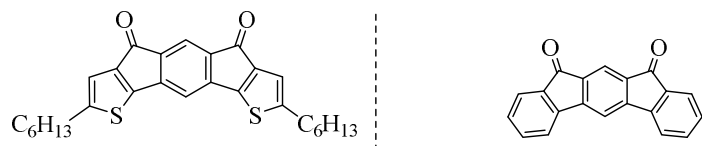

$[2,1-b]-\mathbf{I F}(=\mathbf{O})_{2}$

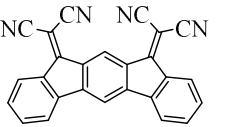

$[2,1-b]-\mathrm{IF}\left(=\mathrm{C}(\mathrm{CN})_{2}\right)_{2}$

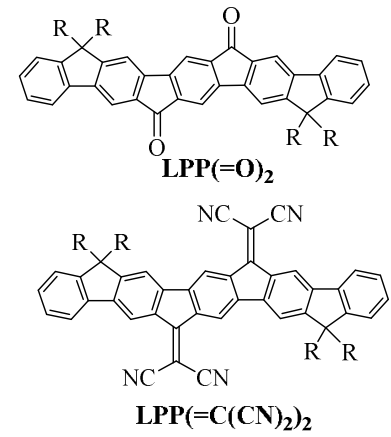

Ladder-pentaphenylene derivatives

Chart 2. Chemical structures of the four IDT derivatives investigated in this work (left) and some structurally related electron-deficient ladder-type molecules previously reported based either on a dihydro[2,1-b]Indeno-meta-Fluorene $([2,1-b]-\mathrm{IF}$, middle $),{ }^{21}$ or on Ladder PentaPhenylene (right). ${ }^{20}$

In this work, we hence aim to report the first member of a new family of OSC constructed on a meta dihydroindacenodithiophene (IDT) core, that is 2,2'-(2,8-dihexyl-4,6-dihydro-s-indaceno[1,2$b: 7,6-b$ ]dithiophene-4,6-diylidene)dimalononitrile (called meta-IDT $\left.\left(=\mathbf{C}(\mathbf{C N})_{2}\right)_{2}\right)$. The properties of this molecule have been studied in detail through a structure properties relationship study with its regioisomer, that is 2,2'-(2,7-dihexyl-4,9-dihydro-s-indaceno[1,2-b:5,6- $b$ ] dithiophene-4,9- 
diylidene)dimalononitrile (para-IDT $\left.\left(=\mathbf{C}(\mathbf{C N})_{2}\right)_{2}\right)$ previously reported in literature by Geng et al ${ }^{50}$ (see isomers structures in blue in Chart 2). Such a study will shed light on the impact of regioisomerism (meta-IDT vs para-IDT) on the electronic properties at the molecular level (electrochemistry, absorption spectroscopy, molecular modelling) and also on the supramolecular arrangement (SWAXS), and finally on the OFET performance and stability. Of particular interest, we notably report herein the significant effect of the self-assembled monolayers (SAMs) of DABT grafted on the gold drain and source electrodes on the OFET performance and stability. In the light of performances and stability obtained (maximum mobility reaching $5.8 \times 10^{-2} \mathrm{~cm}^{2} \mathrm{~V}^{-1} \mathrm{~cm}^{-1}$, high $\mathrm{Id}_{\text {on }} / \mathrm{Id}_{\text {off }}$ of $2.3 \times 10^{7}$ and subthreshold swing of $1.3 \mathrm{~V} / \mathrm{dec}$ ), we believe that the present OFETs can be further used to construct electronic circuits. Additionally, OFETs constructed on a flexible polyethylene naphtalate (PEN) instead of the glass substrate have shown at least similar (with meta-IDT $\left.\left(=\mathbf{C}(\mathbf{C N})_{2}\right)_{2}\right)$ to more than twice better performances (with para-IDT $\left.\left(=\mathbf{C}(\mathbf{C N})_{2}\right)_{2}\right)$ than similar rigid OFETs constructed on glass substrate (maximum mobility reaching $7.1 \times 10^{-2} \mathrm{~cm}^{2} \mathrm{~V}^{-1}$ $\mathrm{cm}^{-1}$, high $\mathrm{Id}_{\text {on }} / \mathrm{Id}_{\text {off }}$ of $4 \times 10^{6}$ and subthreshold swing of $2.6 \mathrm{~V} / \mathrm{dec}$ ) opening large perspective for flexible devices.

\section{Results and discussion:}

\section{Design and synthesis}

The ideal OSC for n-type OFET should possess an electron-deficient $\pi$-conjugated backbone that facilitates close intermolecular $\pi-\pi$ stacking and efficient electron transport, a LUMO level adapted to the cathode electrode potential in order to facilitate the electron injection and the achievement of a stable electron transport, and, finally, suitable non conjugated side-chains to provide an ideal balance between solubility, close intermolecular stacking and high crystallinity in the solid state thin-film. ${ }^{47-48,51-53}$ The molecular design of the present OSCs consists in rigidifying the 1,3- or 1,4-phenylene-dithiophene fragment by two bridges in a syn or anti configuration (Scheme 1). This bridge stiffening should play a role on the planarity and molecular arrangements of the $\pi$-systems leading to different intermolecular $\pi-\pi$ stacking in the solid state. Electronwithdrawing ketones and/or dicyanovinylene functionalities have been introduced on the bridgeheads to ensure a low LUMO energy level and hexyl chains have been attached on the two side-thiophene cores for processability and crystallinity. ${ }^{54}$

The synthetic strategies developed herein are based on the same approach involving in a first step the synthesis of the corresponding ketones meta-IDT $(=\mathbf{O})_{2}$ and para-IDT $(=\mathbf{O})_{2}$. Thus, the synthesis of $\boldsymbol{m e t a}-\mathbf{I D T}(=\mathbf{O})_{2}$ has been envisaged through an efficient route (Scheme 1, A) based on the intramolecular electrophilic bicyclization of the 2,2'-(1,3-phenylene)dithiophene core, 2. 
The ester groups are arranged on the central phenyl ring, avoiding thus isomers formation as previously reported for bridged $\mathrm{para}^{2-3,41,55}$ and meta ${ }^{6}$ terphenyl fragments, namely dihydroindenofluorenes. The present route is hence regioselective and starts with the synthesis of the diethyl-4,6-dibromoisophtalate 1 following a method previously reported in literature (oxidation of the methyl groups of 1,5-dibromo-2,4-dimethylbenzene with potassium permanganate in tert-butyl alcohol and esterification of the resulting dicarboxylic acid in a mixture of ethanol and methanesulfonic acid, yield $55 \%$ ). ${ }^{21}$ Compound $\mathbf{1}$ is further involved in a Stille cross coupling $\left(\mathrm{Pd}\left(\mathrm{PPh}_{3}\right)_{4}, \mathrm{DMF}, 120^{\circ} \mathrm{C}\right)$ with the commercially available tributyl(5hexylthiophen-2-yl)stannane to give the diethyl 4,6-bis(5-hexylthiophen-2-yl)isophthalate 2 (yield $85 \%$ ), with the ester groups in $\alpha$ position of each thiophene unit. Unfortunately, treatment of 2 with methanesulfonic acid as previously described for similar structures, ${ }^{21}$ failed to directly produce meta-IDT $(=\mathbf{O})_{2}$. In the light of literature, another strategy was therefore employed ${ }^{7}$ and ester 2 was first saponificated under basic conditions $\left(\mathrm{NaOH}, \mathrm{EtOH} / \mathrm{H}_{2} \mathrm{O}\right)$ providing the isophtalic acid derivative 3 (62\%). Compound 3 was then converted into its acid dichloride, 4 (oxalyl chloride, DMF, $\mathrm{CH}_{2} \mathrm{Cl}_{2}$ ), not isolated and further involved in a Lewis acid-promoted intramolecular Friedel-Craft acylation $\left(\mathrm{AlCl}_{3}, \mathrm{CH}_{2} \mathrm{Cl}_{2}, 0^{\circ} \mathrm{C}\right.$ to $\left.\mathrm{rt}\right)$ to give the diketone meta$\operatorname{IDT}(=\mathbf{O})_{2}$ with an overall yield of $86 \%$ from 3. Thus, meta-IDT $(=\mathbf{O})_{2}$ was obtained from $\mathbf{1}$ in an efficient three-step synthesis with an overall yield of $45 \%$. Moreover, in the light of literature, the diketone meta-IDT $(=\mathbf{O})_{2}$ can become in the future a versatile intermediate to construct other organic semi-conductors incorporating spirophenylacridine, ${ }^{12,}{ }^{56}$ spiroindoloacridine, $^{16}$ spiroquinolinophenothiazine, ${ }^{57}$ spiroquinolinophenoxazine ${ }^{58}$ for other electronic applications such as OLEDs or PhOLEDs. Finally, the dicyanovinylene units were introduced through a smooth Knoevenagel condensation $\left(30^{\circ} \mathrm{C}, \mathrm{CH}_{2}(\mathrm{CN})_{2}\right.$, pyridine, $\left.\mathrm{CH}_{2} \mathrm{Cl}_{2}\right)$ producing the metaIDT $\left(=\mathbf{C}(\mathbf{C N})_{2}\right)_{2}$ with a high yield $(86 \%)$. It should be mentioned, that the present Knoevenagel condensation was performed in mild conditions and without titanium tetrachloride, frequently used to activate the carbonyl units of sterically hindered molecules. ${ }^{20,50,59-60}$ 
A
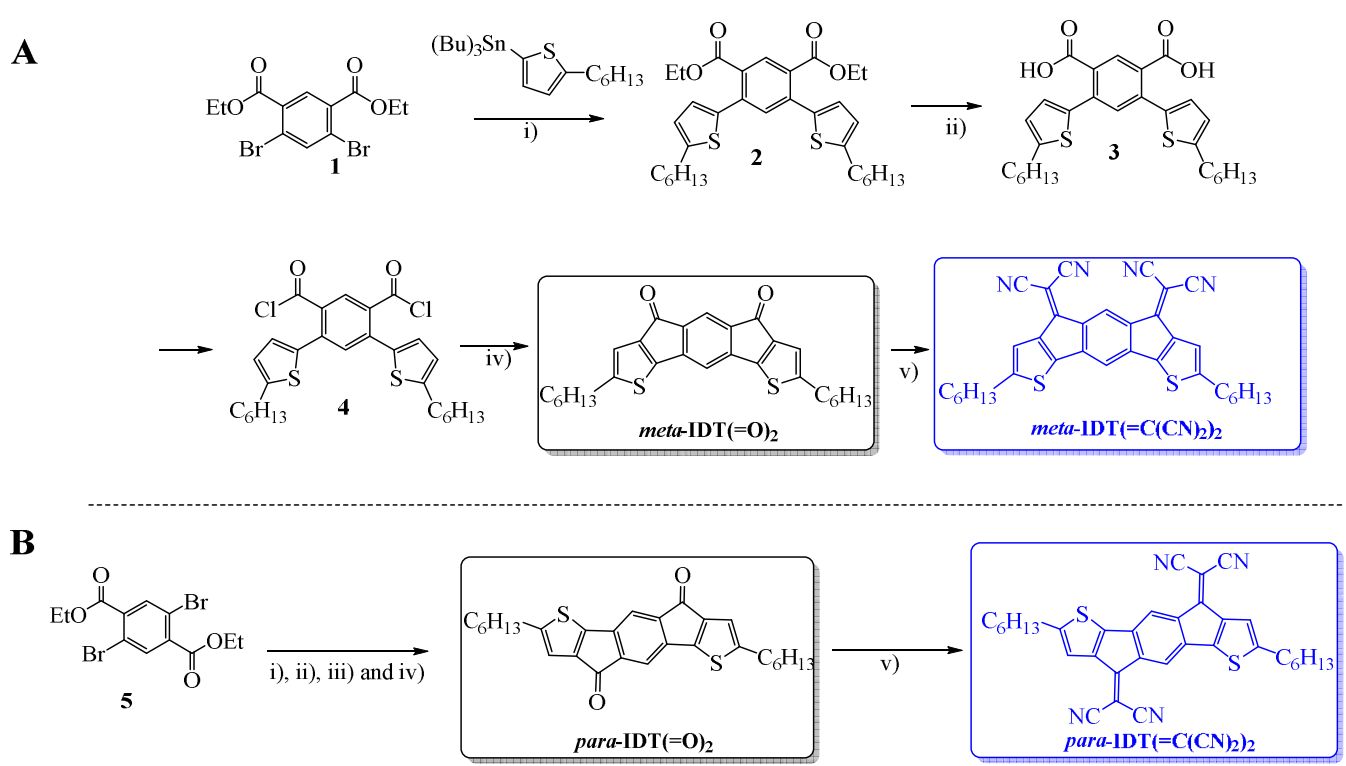

Scheme 1: Synthesis of $m e t a-I D T(=O)_{2} /$ meta-IDT $\left(=\mathrm{C}(\mathrm{CN})_{2}\right)_{2}(\mathrm{~A})$ and para-IDT $(=\mathrm{O})_{2} /$ para-IDT $\left(=\mathrm{C}(\mathrm{CN})_{2}\right)_{2}(\mathrm{~B})$. (i) $\mathrm{Pd}\left(\mathrm{PPh}_{3}\right)_{4}, \mathrm{DMF}, 120^{\circ} \mathrm{C}(85 \%)$; (ii) $\mathrm{NaOH}, \mathrm{EtOH} / \mathrm{H}_{2} \mathrm{O}$, reflux (62\%); (iii) oxalyl chloride, $\mathrm{DMF}, \mathrm{CH}_{2} \mathrm{Cl}_{2} \mathrm{rt}$; (iv) $\mathrm{AlCl}_{3}, \mathrm{CH}_{2} \mathrm{Cl}_{2}, 0^{\circ} \mathrm{C}$ to $\mathrm{rt}\left(86 \%\right.$ over steps (iii) and (iv)); (v) $\mathrm{CH}_{2}(\mathrm{CN})_{2}$, pyridine, $\mathrm{CH}_{2} \mathrm{Cl}_{2}, 30^{\circ} \mathrm{C}$.

The regioisomer para-IDT $\left(=\mathbf{C}(\mathbf{C N})_{2}\right)_{2}$ was synthesized following a similar synthetic procedure, starting from dibromoterephtalate $5{ }^{7}$ and obtained after purification with an overall yield of $21 \%$ (Scheme 1, B). It should be mentioned that both para- and meta-IDT $\left(=\mathbf{C}(\mathbf{C N})_{2}\right)_{2}$ are only very weakly soluble in most common organic solvents. One can note that the yield of the route towards para isomer para-IDT $\left(=\mathbf{C}(\mathbf{C N})_{2}\right)_{2}$ appears to be lower than that of its meta isomer metaIDT $\left(=\mathbf{C}(\mathbf{C N})_{2}\right)_{2}$ mainly due to difficulty of purification in the final step v).

\section{Electrochemical properties}

Electrochemical studies of the four molecules were performed in $\mathrm{Bu}_{4} \mathrm{NPF}_{6} 0.2 \mathrm{M} / \mathrm{CH}_{2} \mathrm{Cl}_{2}$ solutions at a concentration of $10^{-3} \mathrm{M}$ for the diketones (para-IDT $(=\mathbf{O})_{2}$ and $\left.\boldsymbol{m e t a}-\operatorname{IDT}(=\mathbf{O})_{2}\right)$ and in saturated solution for the dicyanovinylene compounds (para-IDT $\left(=\mathbf{C}(\mathbf{C N})_{2}\right)_{2}$ and metaIDT $\left.\left.(=\mathbf{C N})_{2}\right)_{2}\right)$. The cyclic voltammetries $(\mathrm{CVs})$ are presented Figure 1 . It should be noted that both para-IDT $(=\mathbf{O})_{2}$ and para-IDT $\left(=\mathbf{C}(\mathbf{C N})_{2}\right)_{2}$ have been previously studied by Geng et al, ${ }^{50}$ however, the electrochemical investigations were performed in solid state using $\mathrm{CH}_{3} \mathrm{CN}$ as solvent leading hence to different results than those presented herein in solution in dichloromethane.

As presented Figure $1(\mathbf{A}-\mathbf{B})$, both para-IDT $(=\mathbf{O})_{2}$ and meta-IDT $(=\mathbf{O})_{2}$ present in $\mathrm{CH}_{2} \mathrm{Cl}_{2}$, two successive oxidation waves with peak potentials at 1.33 and $1.70 \mathrm{~V}$ for the para isomer and at 1.5 and $2.1 \mathrm{~V}$ for the meta isomer. From their respective onset oxidation potentials $(1.22$ and $1.35 \mathrm{~V}$ resp.), the HOMO energy levels were calculated at $-5.62 \mathrm{eV}$ for $\boldsymbol{p a r a - I D T}(=\mathbf{O})_{2}$ and at $-5.75 \mathrm{eV}$ for $\boldsymbol{m e t a}$-IDT $(=\mathbf{O})_{2}$ (see details in the Supporting Information). The shift of $0.13 \mathrm{eV}$ between the HOMO of the two isomers shows that the angular-shaped meta-IDT core is more difficult to 
oxidize than the linear para-IDT one. This might be assigned to the nature of the linkages. A similar shift has previously been observed between meta- and para-dihydroindenofluorene isomers. ${ }^{6}$ Indeed, the dihydro[1,2-b]indenofluorene, backbone possessing an anti geometry and para linkages is oxidized $0.17 \mathrm{~V}$ before its dihydro[2,1-b]indenofluorene isomer, possessing a syn geometry and meta linkages. This shift may be directly related to the para- or meta-linkages but also to the ring bridging and clearly indicates a shorter $\pi$-conjugation pathway in the meta- than in the para-derivatives. The same trend is hence detected herein indicating a similar effect of the side rings (phenyl in dihydroindenofluorene and thiophene in dihydroindacenodithiophene) on the $\pi$ conjugation length. This indicates the importance of the linkages on the energy levels of the frontiers orbitals. This will be confirmed by theoretical calculations presented below.

None of the two oxidation processes were reversible, showing the high reactivity of the oxidized species (radical-cation and dication). In contrast, in the cathodic range, the reduction of paraIDT $(=\mathbf{O})_{2}$ and $\boldsymbol{m e t a}-\mathbf{I D T}(=\mathbf{O})_{2}$ present two well defined reversible waves with maxima at -0.95 and $-1.43 \mathrm{~V}$ and at -1.02 and $-1.53 \mathrm{~V}$, respectively. The two reduction processes occur at similar potential values than those previously reported for (i) a comparable para-IDT $(=\mathbf{O})_{2}$ with no solubilizing alkyl chain on the thienyl units $(-0.91$ and $-1.49 \mathrm{~V}$, see molecular structure in the Supporting Information : Chart S1), ${ }^{61}$ (ii) the dihydroindefluorenones possessing 3 bridged phenyl rings, namely para- $\mathbf{I F}(=\mathbf{O})_{2} \quad(-0.98$ and $-1.38 \mathrm{~V}$, see molecular structure in the Supporting Information : Chart S1) $)^{7}$ and $\mathbf{m e t a}-\mathbf{I F}(=\mathbf{O})_{2}(-0.98$ and $-1.45 \mathrm{~V}$, see molecular structures in Chart $2)^{21}$ and (iii) the pentaphenylenones $\mathbf{L P P}(=\mathbf{O})_{2}(-1.07$ and $-1.52 \mathrm{~V}$, see molecular structures in Chart 2$)^{7}$ and diphenyl-LPP $(=\mathbf{O})_{2}(-1.0$ and $-1.35 \mathrm{~V}$, see structure in the Supporting Information : Chart S1) possessing 5 bridged phenyl rings. ${ }^{62}$ Thus, the nature (phenyl $v s$ thiophene) and the number of constituted units do not significantly modify the reduction potentials of this type of compounds, clearly indicating a reduction centred on the carbonyl groups and not on the $\pi$-conjugated core. Thus, after the two successive reduction processes, the quinonoidal dianions were obtained. ${ }^{62}$ From the onset reduction potentials respectively measured at -0.83 and $-0.84 \mathrm{~V}$ for $\boldsymbol{p a r a}$-IDT $(=\mathbf{O})_{2}$ and $\boldsymbol{m e t a}$-IDT $(=\mathbf{O})_{2}$, we determined their LUMO energy levels lying at -3.57 and $-3.56 \mathrm{eV}$. These LUMO energy levels appear to be deep and highlight the strong electronwithdrawing character of the ketones groups. Thus, the deep LUMO energy levels of both molecules lead to a short electrochemical energy gap $\Delta \mathrm{E}_{\mathrm{el}}$ of $2.05 \mathrm{eV}$ for para-IDT $(=\mathbf{O})_{2}$ and 2.19 $\mathrm{eV}$ for $\boldsymbol{m e t a}$-IDT $(=\mathbf{O})_{2}$. It is noteworthy that the difference between the two gaps comes from the restriction of conjugation in the meta isomer compared to its para isomer and is therefore clearly induced by the modulation of the HOMO levels and hence by the nature of the $\pi$-conjugated system. 
A

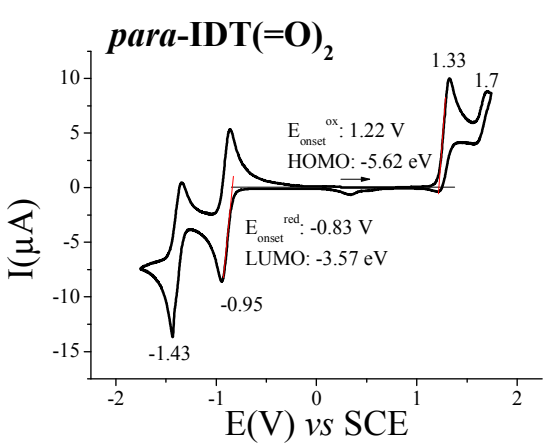

C

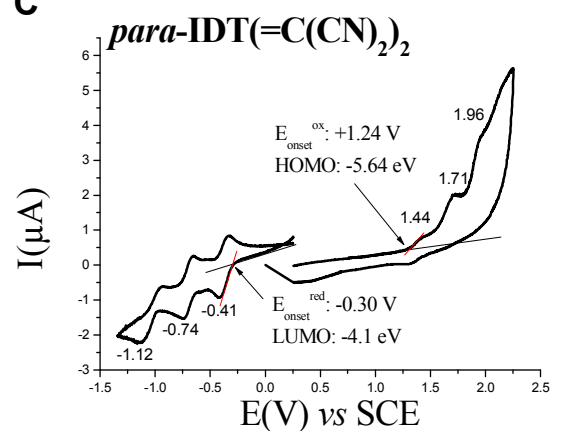

B

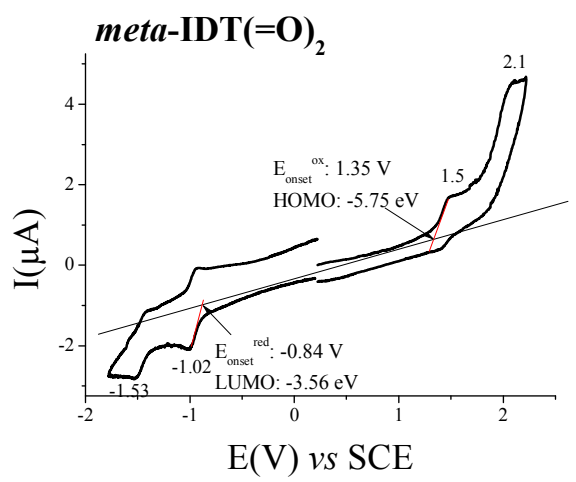

D

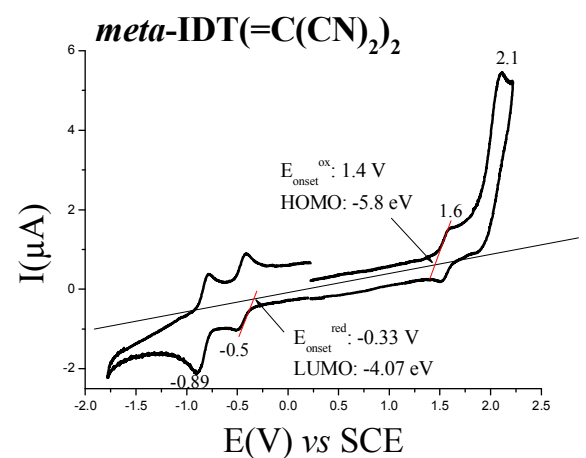

Figure 1. Cyclic voltammetry of para-IDT $(=\mathbf{O})_{2}(A)$ and meta-IDT $(=\mathbf{O})_{2}(\mathbf{B})\left(10^{-3} \mathrm{M}\right)$ and of para-IDT $\left(=\mathbf{C}(\mathbf{C N})_{2}\right)_{2}$ $(\mathbf{C})$ and meta-IDT $\left(=\mathbf{C}(\mathbf{C N})_{2}\right)_{2}$ (D) (saturated solution) recorded in $\mathrm{CH}_{2} \mathrm{Cl}_{2}+\mathrm{Bu}_{4} \mathrm{NPF}_{6} 0.2 \mathrm{M}$, sweep-rate $100 \mathrm{mV} \cdot \mathrm{s}^{-1}$. Platinum disk (Ø: $1 \mathrm{~mm})$ working electrode.

As presented in Figure $1(\mathbf{C}-\mathbf{D})$, para-IDT $\left(=\mathbf{C}(\mathbf{C N})_{2}\right)_{2}$ presents three successive oxidation processes with maxima at $1.44,1.71$ and $1.96 \mathrm{~V}$, whereas its isomer meta-IDT $\left(=\mathbf{C}(\mathbf{C N})_{2}\right)_{2}$ only presents two oxidation waves with maxima at 1.6 and $2.1 \mathrm{~V}$. For both molecules, only the first oxidation process is reversible indicating the stability of the radical cations at the CV timescale. As this behaviour was not observed for $\mathbf{L P P}\left(=\mathbf{C}(\mathbf{C N})_{2}\right)_{2}$ ) (which present two successive reversible oxidation processes $^{20}$ ) neither for meta- $\mathbf{I F}\left(=\mathbf{C}(\mathbf{C N})_{2}\right)_{2}$ (which oxidation is not observed before the oxidation of the electrolytic medium, ${ }^{21}$ see molecular structures in Chart 2), this feature can be assigned to the IDT core. The onset oxidation potentials are respectively measured at 1.24 and $1.40 \mathrm{~V}$, leading to HOMO energy level lying at $-5.64 \mathrm{eV}$ for para-IDT $\left(=\mathbf{C}(\mathbf{C N})_{2}\right)_{2}$ and at $-5.80 \mathrm{eV}$ for meta-IDT $\left(=\mathbf{C}(\mathbf{C N})_{2}\right)_{2}$. Thus, a small shift of $0.16 \mathrm{eV}$ is observed between the HOMO levels of the two isomers, in accordance with that observed for the diketone derivatives, confirming that the conjugation of the meta isomer is more restricted than the conjugation of the para isomer. Moreover, only a very weak shift of the HOMO energy levels is observed from diketone to dicyanovinylene derivatives $(0.02 \mathrm{eV}$ and $0.05 \mathrm{eV}$ in the para and the meta series respectively), indicating that the dicyano-derivatives are only slightly more difficult to oxidize than their 
diketone derivatives. Thus, in the anodic range, the switch of the electron-withdrawing groups from carbonyl to dicyanovinylene units only has an extremely weak effect on the oxidation processes. The same effect was also detected in the LPP series which displays a weak HOMO level modulation between $\mathbf{L P P}(=\mathbf{O})_{2}(\mathrm{HOMO}:-5.67 \mathrm{eV})$ and $\mathbf{L P P}\left(=\mathbf{C}(\mathbf{C N})_{2}\right)_{2}(\mathrm{HOMO}:-5.79$ $\mathrm{eV})^{20}$ and in the dihydroindenofluorene series for which the HOMO of the meta-IF $(=\mathbf{O})_{2}(-5.96$ $\mathrm{eV})$ is only shifted by $0.05 \mathrm{eV}$ compared to that of $\boldsymbol{m e t a}-\mathbf{I F}\left(=\mathbf{C}(\mathbf{C N})_{2}\right)_{2}(-5.91 \mathrm{eV}) .{ }^{21}$ This feature confirms that the first electron transfer in oxidation occurs on the $\pi$-conjugated backbone with no (or very weak) influence of the bridge. This will be explained by the distribution of the HOMO obtained by molecular modelling (see below). The comparison of the HOMO of meta$\mathbf{I F}\left(=\mathbf{C}(\mathbf{C N})_{2}\right)_{\mathbf{2}}(-5.91 \mathrm{eV})^{21}$ to that of meta-IDT $\left(=\mathbf{C}(\mathbf{C N})_{2}\right)_{\mathbf{2}}(-5.8 \mathrm{eV})$ shows that the change of the two external phenyl units in $\boldsymbol{m e t a}-\mathbf{I F}\left(=\mathbf{C}(\mathbf{C N})_{2}\right)_{2}$ by two thienyl units in meta-IDT $\left(=\mathbf{C}(\mathbf{C N})_{2}\right)_{2}$ renders slightly easier the oxidation processes. This is in line with the electron rich character of thiophene ring.

In reduction, para-IDT $\left(=\mathbf{C}(\mathbf{C N})_{2}\right)_{2}$ presents three successive reduction processes with maxima at $0.41,-0.74$ and $-1.12 \mathrm{~V}$, whereas meta-IDT $\left(=\mathbf{C}(\mathbf{C N})_{2}\right)_{2}$ only presents two successive reduction processes with maxima in the same potential range at -0.5 and $-0.89 \mathrm{~V}$. Thus, the two first reduction waves, both occur at a less negative potential than those of their related diketone derivatives. From their onset reduction potentials measured at -0.3 and $-0.33 \mathrm{~V}$ resp ., the LUMO energy level appears to be very deep, lying at $-4.1 \mathrm{eV}$ for para-IDT $\left(=\mathbf{C}(\mathbf{C N})_{2}\right)_{2}$ and at $-4.07 \mathrm{eV}$ for meta-IDT $\left(=\mathbf{C}(\mathbf{C N})_{2}\right)_{2}$. Thus, the LUMO energy of the IDT compounds is remarkably more affected by the substitution (shift of ca $0.5 \mathrm{eV}$ ) than the HOMO energy (shift of ca $0.05 \mathrm{eV}$, see above). These electrochemical data suggest that the LUMOs are localized on the bridges, rendering the LUMO levels more sensitive to bridges functionalization $\left(=\mathrm{O} v s=\mathrm{C}(\mathrm{CN})_{2}\right)$. Oppositely, as the HOMO energy levels are strongly less sensitive to bridges functionalization, they are surely more spread out on the IDT core. This finding, which will be confirmed through theoretical calculations, indicates that the bridge substitution allows selectively tuning the LUMO energy levels with only a weak alteration of their HOMO levels leading to very short electrochemical energy gap, $1.54 \mathrm{eV}$ for para-IDT $\left(=\mathbf{C}(\mathbf{C N})_{2}\right)_{2}$ and at $1.73 \mathrm{eV}$ for metaIDT $\left(=\mathbf{C}(\mathbf{C N})_{2}\right)_{2}$. These gaps are significantly contracted compared to their diketone analogues due to the decrease of the LUMO energy level. These electrochemical data (HOMO, LUMO and $\Delta \mathrm{E}^{\mathrm{el}}$ ) are summarized in Table 1 and schematized in green in Figure 2. 
Table 1. Summary of the selected electronic properties of the four IDT-derivatives

\begin{tabular}{|c|c|c|c|c|c|c|c|c|c|}
\hline & \multicolumn{5}{|c|}{ Electrochemical studies } & \multicolumn{3}{|c|}{ Theoretical calculations } & \multirow{2}{*}{$\begin{array}{c}\begin{array}{c}\text { Optical } \\
\text { studies }\end{array} \\
\begin{array}{c}\Delta \mathrm{E}_{\mathrm{op}} \\
(\mathrm{eV})^{\mathrm{d}}\end{array}\end{array}$} \\
\hline & $\begin{array}{c}\begin{array}{c}\text { Oxidation } \\
\text { peaks }\end{array} \\
-\mathrm{E}^{\text {ox }}{ }_{\text {onset }} \\
(\mathrm{V})^{\mathrm{a}}\end{array}$ & $\begin{array}{c}\begin{array}{c}\text { Reduction } \\
\text { peaks }\end{array} \\
-\mathrm{E}^{\text {red }}{ }_{\text {onset }}^{\mathrm{b}} \\
(\mathrm{V})^{\mathrm{a}}\end{array}$ & $\begin{array}{l}\text { HOMO } \\
(\mathrm{eV})^{\mathrm{b}}\end{array}$ & $\begin{array}{l}\text { LUMO } \\
(\mathrm{eV})^{\mathrm{b}}\end{array}$ & $\begin{array}{l}\Delta \mathrm{E}_{\mathrm{el}} \\
(\mathrm{eV})^{\mathrm{c}}\end{array}$ & $\begin{array}{c}\text { HOMO } \\
(\mathrm{eV})\end{array}$ & $\begin{array}{c}\text { LUMO } \\
(\mathrm{eV})\end{array}$ & $\begin{array}{c}\Delta \mathrm{E}_{\text {theo }} \\
(\mathrm{eV})\end{array}$ & \\
\hline para-IDT $(=\mathbf{O})_{2}$ & $\begin{array}{c}1.33,1.70 \\
---- \\
1.22\end{array}$ & $\begin{array}{c}-0.95,-1.43 \\
--0.83\end{array}$ & -5.62 & -3.57 & 2.05 & -5.80 & -3.22 & 2.58 & 1.85 \\
\hline para-IDT $\left(=\mathrm{C}(\mathrm{CN})_{2}\right)_{2}$ & $\begin{array}{c}1.44,1.71 \\
1.96 \\
-0--- \\
1.24 \\
\end{array}$ & $\begin{array}{c}-0.41,- \\
0.74,-1.12 \\
----- \\
-0.3 \\
\end{array}$ & -5.64 & -4.10 & 1.54 & -6.20 & -4.21 & 1.99 & 1.29 \\
\hline$m e t a-\operatorname{IDT}(=\mathrm{O})_{2}$ & $\begin{array}{c}1.5,2.1 \\
-1.35 \\
\end{array}$ & $\begin{array}{c}-1.02,-1.53 \\
-0 .- \\
-0.84 \\
\end{array}$ & -5.75 & -3.56 & 2.19 & -5.93 & -3.18 & 2.75 & 2.04 \\
\hline$m e t a-\operatorname{IDT}\left(=\mathrm{C}(\mathrm{CN})_{2}\right)_{2}$ & $\begin{array}{c}1.6,2.1 \\
----- \\
1.40 \\
\end{array}$ & $\begin{array}{c}-0.5,-0.89 \\
---- \\
-0.33 \\
\end{array}$ & -5.80 & -4.07 & 1.73 & -6.37 & -4.06 & 2.31 & 1.57 \\
\hline
\end{tabular}

${ }^{a} v_{S} \mathrm{SCE},{ }^{\mathrm{b}}$ Calculated from onset oxidation/reduction potential observed from $\mathrm{CV}$ (Figure 1). ${ }^{\mathrm{c}} \Delta \mathrm{E}_{\mathrm{el}}=\mathrm{HOMO}-$ LUMO from electrochemical data. ${ }^{\mathrm{d}} \mathrm{hc} / \lambda=1239.84 / \lambda$ (in $\mathrm{nm}$ ) from absorption spectrum, $\lambda$ being the low energy absorption band edge.

Molecular modelling has been performed through DFT calculations at the Gaussian 09 B3LYP/6$311+\mathrm{G}(\mathrm{d}, \mathrm{p})$ level of theory, Figure 2). The HOMO of the four compounds are dispersed on the IDT core. This feature shed light on the small HOMO energy modulation observed through electrochemical experiments between the ketone and the dicyanovinylene molecules. An important difference is nevertheless detected between the two isomers. Indeed, for the para isomers, there is a delocalization over the whole IDT core due to the central phenyl para linkage, which maximises the $\pi$-conjugation. However, an inspection of the shape of the HOMO of meta isomers reveals a $\pi$ conjugation interruption at the two opposite carbon atoms of the central phenyl ring (nodal plane), leading to a lower HOMO energy level than that of its para isomers. Meta-IDT $\left(=\mathbf{C}(\mathbf{C N})_{2}\right)_{2}$ bears hence a strong resemblance to the cyclopentathiophene. Interestingly, the first oxidation of the spiro[fluorene-9,4'-[4H] indeno[3,2-b] thiophene] ${ }^{63}$ (see Spiro-FIT molecular structure in the Supporting Information: Chart S1) which is directed by the oxidation of the indenothiophene core occurs with a maximum of current at $1.67 \mathrm{~V} v s$ SCE, close to the peak potential measured for meta-IDT $\left(=\mathbf{C}(\mathbf{C N})_{2}\right)_{2}(1.6 \mathrm{~V}$, see Table 1$)$.

In contrast, the localisations of the LUMO are strongly different and much more sensitive to the bridge substitution. Indeed, in both ketones, the LUMO are mainly localised on the two cyclopentadienone cores whereas in dicyanovinylenes molecules, the LUMOs are instead 
essentially localized on the cyclopentadiene/dicyanovinylene (Figure 2, top). These results are in accordance with the assignment of the different electron transfers exposed in the electrochemical part and show why the LUMO energy levels are impressively more influenced by the bridges than the HOMO levels are. Interestingly, theoretical calculations also confirm the experimental trends in term of HOMO/LUMO energy levels and energy gap modulation (see values in blue Figure 2). Thus, there is an impressive gap difference between ketones and dicyanovinylenes of $0.59 \mathrm{eV}$ for the para derivatives (left) and of $0.44 \mathrm{eV}$ for the meta derivatives (right). This gap variation, induced by a strong decrease of the LUMO levels (lowering of $-0.99 \mathrm{eV}$ in the para series and of $0.88 \mathrm{eV}$ in the meta series) is comparable to that obtained with electrochemical data (decrease of $0.53 \mathrm{eV}$ for the para-series and of $0.51 \mathrm{eV}$ for the meta-series).

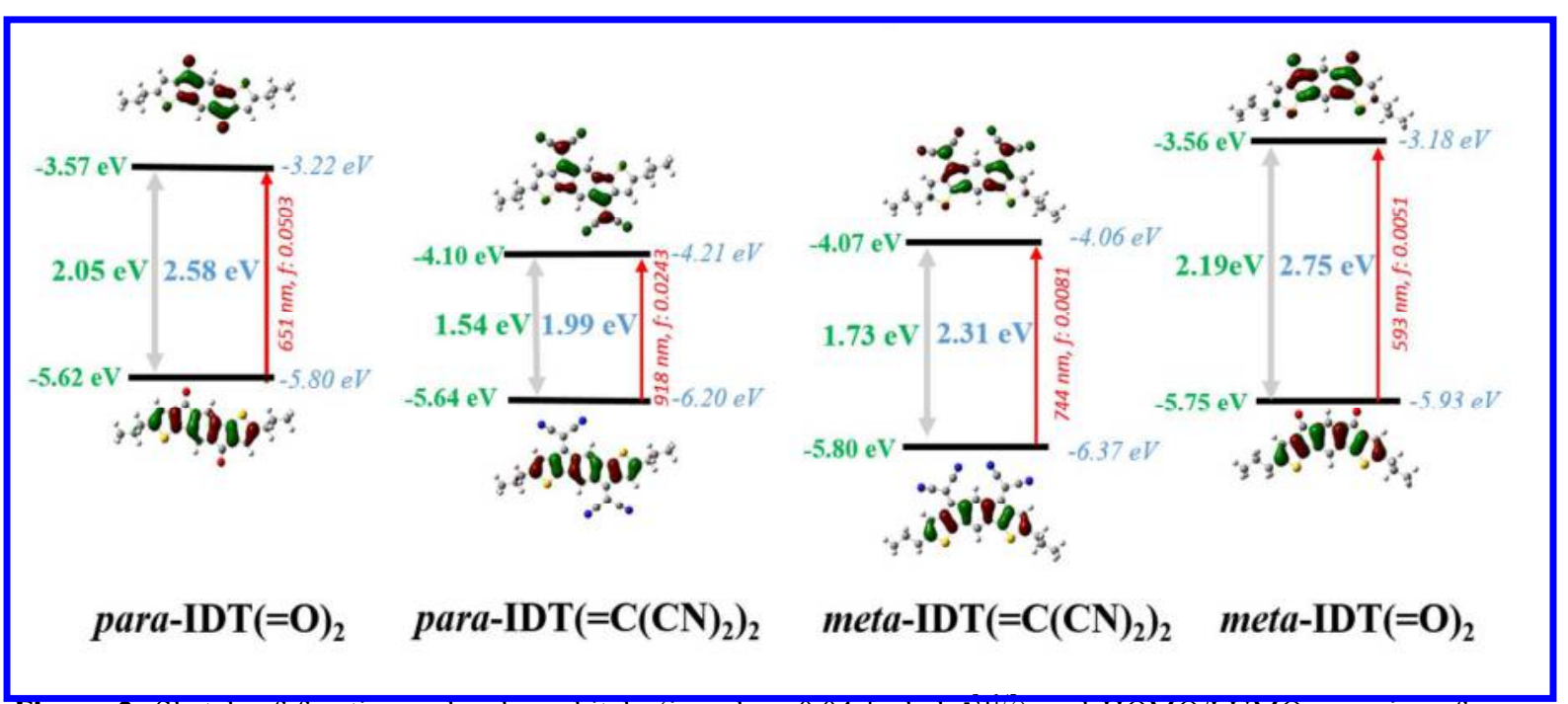

Figure 2. Sketch of frontier molecular orbitals (isovalue: 0.04 [e bohr $\left.{ }^{5}\right]^{12}$ ) and HOMO/LUMO energies of para$\operatorname{IDT}(=0)_{2}$, para-IDT $\left(=\mathrm{C}(\mathrm{CN})_{2}\right)_{2}$, meta-IDT $\left(=\mathrm{C}(\mathrm{CN})_{2}\right)_{2}$ and meta-IDT $(=\mathrm{O})_{2}$ obtained from electrochemical data (in green) and from DFT calculations (in blue). First electronic transition calculated by TD-DFT B3LYP/6$311+\mathrm{G}(\mathrm{d}, \mathrm{p})$ in red. 


\section{$U V$-Vis absorption spectra}

UV-Vis absorption spectra of the two $\operatorname{IDT}(=\mathbf{O})_{2}$ derivatives were recorded in cyclohexane whereas, due to solubility considerations, those of the $\mathbf{I D T}\left(=\mathbf{C}(\mathbf{C N})_{2}\right)_{2}$ derivatives were recorded in THF (Figure 3).
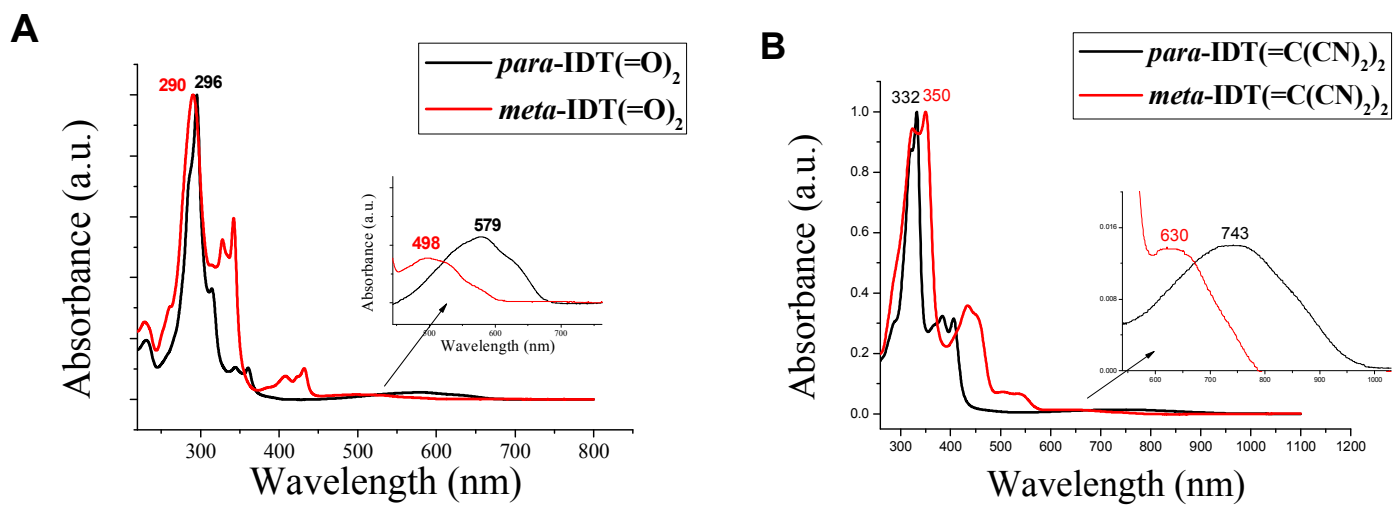

Figure 3. Normalized absorption spectra of para-IDT $(=\mathbf{O})_{2}$ and meta-IDT $(=\mathbf{O})_{2}$ isomers recorded in cyclohexane (A) and of $\boldsymbol{m e t a}-\operatorname{IDT}\left(=\mathbf{C}(\mathbf{C N})_{2}\right)_{2}$ and para-IDT $\left(=\mathbf{C}(\mathbf{C N})_{2}\right)_{2}$ isomers recorded in saturated solutions in THF (B).

Absorption spectra of both IDT $(=\mathbf{O})_{2}$ derivatives are well defined, with fine absorption bands between 250 and $450 \mathrm{~nm}$, signing the high rigidity of the $\pi$-conjugated IDT backbones. Both molecules also present a weak absorption band at higher wavelength (between 450 and $700 \mathrm{~nm}$ ). This very weak band is characteristic of a $n-\pi^{*}$ transition and in the light of TD-DFT (see in red, Figure 2) has been assigned a HOMO/LUMO transition possessing a very weak oscillator strength

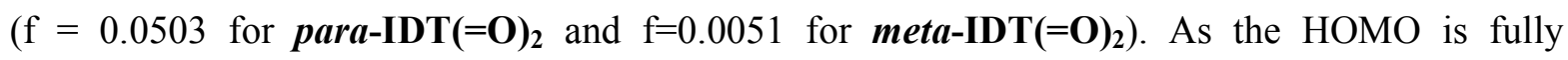
localized on the IDT core and the LUMO on the cyclopentadienone unit, this transition presents a strong charge transfer character. The optical energy gap $\left(\Delta \mathrm{E}^{\mathrm{opt}}\right)$ of the molecules was calculated from the onset of the low energy absorption band (inset Figure $3 \mathrm{~A}$ ). These $\Delta \mathrm{E}^{\mathrm{opt}}$ are of $1.84 \mathrm{eV}$ for para-IDT( $=\mathbf{O})_{2}\left(\lambda_{\text {onset }}: 674 \mathrm{~nm}\right)$ and of $2.04 \mathrm{eV}$ for meta-IDT( $\left.=\mathbf{O}\right)_{2}\left(\lambda_{\text {onset }}: 608 \mathrm{~nm}\right)$. The 0.20 $\mathrm{eV}$ difference between the two $\Delta \mathrm{E}^{\mathrm{opt}}$ is in the same range than that obtained from electrochemical data $(0.14 \mathrm{eV})$ and from molecular modelling $(0.17 \mathrm{eV})$. This evidences that the HOMO/LUMO difference is clearly involved in $\Delta \mathrm{E}^{\mathrm{opt}}$ (Table 1).

Both IDT $\left(=\mathbf{C}(\mathbf{C N})_{2}\right)_{2}$ derivatives present a less resolved UV-visible spectrum (Figure 3B) with broader absorption bands than those observed for $\mathbf{I D T}(=\mathbf{O})_{2}$ derivatives. The bathochromic shift from ketones to dicyanovinylenes observed for the high energy bands can be assigned to an extension of the conjugation. A weak and broad absorption band is also detected at low energy (at $630 \mathrm{~nm}$ for $\boldsymbol{m e t a}-\mathbf{I D T}\left(=\mathbf{C}(\mathbf{C N})_{2}\right)_{2}$ and at $743 \mathrm{~nm}$ para-IDT $\left(=\mathbf{C}(\mathbf{C N})_{2}\right)_{2}$, inset Figure 3B $)$, assigned in the light of TD-DFT to a HOMO/LUMO transition possessing a weak oscillator strength ( $\mathrm{f}=$ 
0.0081 and 0.0243 , resp., see in red Figure 2). Thus, the bathochromic shift of this band upon dicyanovinylene functionalization is mainly due to the strong decrease of the LUMO energy level, ${ }^{20,64-65}$ resulting in an optical gap $\Delta \mathrm{E}^{\mathrm{opt}}$ contraction of ca $0.5 \mathrm{eV}$ from $2.04 \mathrm{eV}$ for $\boldsymbol{m e t a}$ $\operatorname{IDT}(=\mathbf{O})_{2}$ to $1.57 \mathrm{eV}$ for $\boldsymbol{m e t a}-\mathbf{I D T}\left(=\mathbf{C}(\mathbf{C N})_{2}\right)_{2}$ and from $1.85 \mathrm{eV}$ for $\boldsymbol{p a r a}-\mathbf{I D T}(=\mathbf{O})_{2}$ to $1.29 \mathrm{eV}$ for para-IDT $\left(=\mathrm{C}(\mathrm{CN})_{2}\right)_{2}$.

In the higher energy range, meta-derivatives present additional absorption bands between 350 and $450 \mathrm{~nm}$ for $\boldsymbol{m e t a}-\operatorname{IDT}(=\mathbf{O})_{2}$ and between 400 and $600 \mathrm{~nm}$ for $\boldsymbol{m e t a}-\mathbf{I D T}\left(=\mathbf{C}(\mathbf{C N})_{2}\right)_{2}$, those bands are also pointed by theoretical calculations at $427 \mathrm{~nm}$ for $\boldsymbol{m e t a - I D T}(=\mathbf{O})_{2}$ and at 464 and $545 \mathrm{~nm}$ for $\boldsymbol{m e t a}-\mathbf{I D T}\left(=\mathbf{C}(\mathbf{C N})_{2}\right)_{2}$ and are assigned to HOMO-1 vs LUMO and HOMO $v_{s}$ LUMO+1 transitions (see more details in the Supporting Information). TD-DFT of the four compounds are given in the Supporting Information (Figures S10-S17).

Thermally evaporated thin films of meta-IDT $\left(=\mathbf{C}(\mathbf{C N})_{2}\right)_{2}$ and para-IDT $\left(=\mathbf{C}(\mathbf{C N})_{2}\right)_{2}$ (thickness: 60 $\mathrm{nm}$, prepared in the same conditions than for the devices presented below) present respectively an onset absorption measured at $856 \mathrm{~nm}$ and $1016 \mathrm{~nm}$ leading to $\Delta \mathrm{E}^{\mathrm{opt}}$ of $1.45 \mathrm{eV}$ and $1.22 \mathrm{eV}$ (Figure 4). There is hence a slight gap contraction from solution to solid state surely due to different molecular arrangements (for meta-IDT $\left(=\mathbf{C}(\mathbf{C N})_{2}\right)_{2}$ from 1.57 to $1.45 \mathrm{eV}$ and for paraIDT $\left(=\mathbf{C}(\mathbf{C N})_{2}\right)_{2}$ from 1.29 to $\left.1.22 \mathrm{eV}\right)$

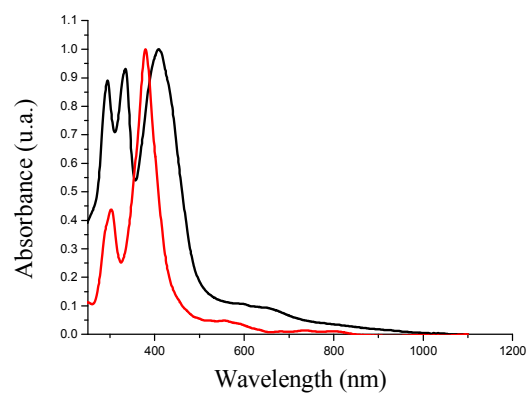

Figure 4: Absorption spectra of thermally evaporated thin films $(60 \mathrm{~nm})$ of $\boldsymbol{m e t a}$-IDT $\left(=\mathbf{C}(\mathbf{C N})_{2}\right)_{2}$ (red line) and paraIDT $\left(=\mathbf{C}(\mathbf{C N})_{2}\right)_{2}$ (black line).

\section{Self-organization properties}

The thermal behaviour of $\operatorname{IDT}(=\mathbf{O})_{2}$ and $\mathbf{I D T}\left(=\mathbf{C}(\mathbf{C N})_{2}\right)_{2}$ compounds were investigated by polarizing optical microscopy (POM), thermogravimetric analysis (TGA), differential scanning calorimetry (DSC) and small and wide angle X-ray scattering (SWAXS). The four derivatives are birefringent and pasty solids at room temperature but show different thermal behaviours (Figure 5): while the two IDT $(=\mathbf{O})_{2}$ melt directly into the isotropic liquid at around $145^{\circ} \mathrm{C}(($ meta$\left.\operatorname{IDT}(=\mathbf{O})_{2} ; \Delta \mathrm{H}=53 \mathrm{~J} / \mathrm{g}\right)$ and $172^{\circ} \mathrm{C}\left(\left(\boldsymbol{p a r a}-\operatorname{IDT}(=\mathbf{O})_{2} ; \Delta \mathrm{H}=66 \mathrm{~J} / \mathrm{g}\right)\right.$, the two $\operatorname{IDT}\left(=\mathbf{C}(\mathbf{C N})_{2}\right)_{2}$ are 
1

2

3

4

5

still birefringent and pasty at $300^{\circ} \mathrm{C}$. The liquid states of both $\mathbf{I D T}\left(=\mathbf{C}(\mathbf{C N})_{2}\right)_{2}$ are therefore out of reach, especially as $300^{\circ} \mathrm{C}$ is also the temperature above which TGA curves show significant weight losses due to the onset of the degradation (the five percent weight loss limit is crossed around $350^{\circ} \mathrm{C}$, at experimental conditions of $5^{\circ} \mathrm{C} / \mathrm{min}$ ramps and of air as sweep gas; Figures S1$\mathrm{S} 3$ in the Supporting Information). The two $\operatorname{IDT}(=\mathbf{O})_{2}$ are on the contrary stable over broad temperature ranges in the liquid state (weight loss and degradation start above $250^{\circ} \mathrm{C}$, and the five percent limit is crossed around $300^{\circ} \mathrm{C}$ ). Such considerable delay (or disappearance) of the liquid state due to diCN is in line with previous results on other compounds and proceeds from the strong intermolecular dipole-dipole and $\pi-\pi$ interactions introduced by these groups ${ }^{[21]}$ This feature may induce efficient electron hopping and hence high charge carrier mobility and is therefore promising for OFET applications (see below).

Despite the maintenance of the pasty birefringent textures, the first heating run DSC curves of both IDT $\left(=\mathbf{C}(\mathbf{C N})_{2}\right)_{2}$ show a big endothermic peak at practically the same temperature and with comparable integrations as the melting transition of $\operatorname{IDT}(=\mathbf{O})_{2}$ analogues $\left(\boldsymbol{m e t a}-\mathrm{IDT}\left(=\mathbf{C}(\mathrm{CN})_{2}\right)_{2}\right.$ : $145^{\circ} \mathrm{C}$ and $\Delta \mathrm{H}=48 \mathrm{~J} / \mathrm{g} ;$ para-IDT $\left(=\mathbf{C}(\mathbf{C N})_{2}\right)_{2}: 170^{\circ} \mathrm{C}$ and $\Delta \mathrm{H}=30 \mathrm{~J} / \mathrm{g}$ ) (Figure 5). These enthalpy changes are hardly understood by crystal phase's transformations and the corresponding peaks must consequently indicate a melting process to a mesophase. The molecular design was actually optimized for mesomorphism: the two alkyl tails terminating a rod- or lath-shaped conjugated mesogen confers a "calamitic" or "sanidic" architecture ${ }^{66}$ to the materials. Mesogens and alkyl tails naturally nanosegregate from each other in alternating domains, and mesophases commonly occur when aliphatic chains melt to liquid-like lateral packing while mesogens maintain some long-range correlated order. ${ }^{67-68} \mathbf{I D T}\left(=\mathbf{C}(\mathbf{C N})_{2}\right)_{2}$ and $\mathbf{I D T}(=\mathbf{O})_{2}$ have identical terminal chains which represent nearly the same volume fraction with respect to the mesogen, and it is therefore not surprising to find close melting temperatures for aliphatic domains. The intrinsic properties of both mesogens then come to the forefront: collapse of any long-range order and direct transition to liquid arise for the weakly interacting carbonyl-functionalized mesogens, whereas the cohesively self-associated dicyanovinylene-functionalized mesogens presumably maintain a long-range correlated structure across the liquid aliphatic interlayers. This structure would explain the birefringence and the high viscosity, and corollary clarify the behaviour on cooling and second heating: crystallization with small supercooling by starting from liquid $\mathbf{I D T}(=\mathbf{O})_{2}$, freezing of the viscous mesophase of IDT $\left(=\mathbf{C}(\mathbf{C N})_{2}\right)_{2}$ on cooling (see Figures S4-S6 in the Supporting Information). 


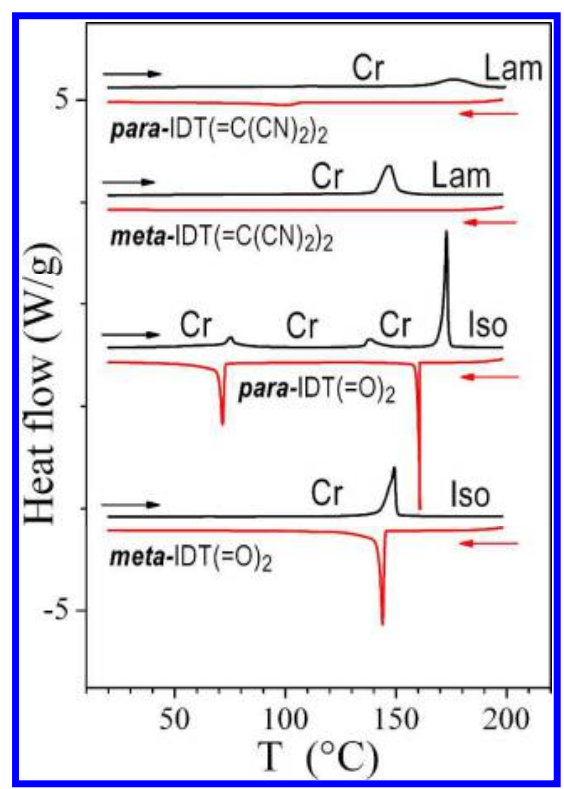

Figure 5: DSC traces of IDT $(=\mathbf{O})_{2}$ and $\mathbf{I D T}\left(=\mathbf{C}(\mathbf{C N})_{2}\right)_{2}$ regioisomers (1st heating run (black) and cooling run (red) at $5^{\circ} \mathrm{C} / \mathrm{Min}$, endotherm up); Cr: crystalline phase; Iso: isotropic liquid; Lam: three-dimensional lamellar mesophase.

SWAXS patterns confirm these interpretations. In the pristine state, the four derivatives effectively give patterns typical of crystalline phases, with exclusively sharp reflections distributed over the whole scattering window (Figure 6 ). On heating above melting, IDT $(=\mathbf{O})_{2}$ patterns become characteristic of nanosegregated liquids, with a broad small-angle scattering maximum coming from the alternation of molten domains of mesogens and chains, besides a broad wide-angle scattering maximum due to lateral distances inside domains (position of both maximums: 18-20 $\AA$ and 4-5 $\AA$ ).

Patterns above the melting of $\mathbf{I D T}\left(=\mathbf{C}(\mathbf{C N})_{2}\right)_{2}$ isomers contain a $(00 l)$ reflection series in the small-angle range and overlapping broad scattering and sharp reflections in the wide-angle range, which definitively confirms the identification to a three-dimensional lamellar mesophase. These lamellae emerge from the alternation of layers of molten chains, at the origin of the broad scattering $h_{c h}$, and from layers of regularly arranged mesogens. As previously encountered for closely related systems, ${ }^{67-68}$ the aliphatic interlayers are not sufficient to blur out the positional correlations between successive conjugated layers and leave crossed reflections $(h k l)$ of a threedimensional superstructure. Similar patterns are obtained after cooling to room temperature confirming the freezing of the mesophase structures, as already deduced from DSC (see Figures S4-S6 in the Supporting Information). The three dimensional cells remain unsolved so far, but the packing geometry can be investigated through the combination of the lamellar periodicities (metaIDT $\left(=\mathbf{C}(\mathbf{C N})_{2}\right)_{2}: \mathrm{d}=24.1 \AA$; para $\left.-\mathbf{I D T}\left(=\mathbf{C}(\mathbf{C N})_{2}\right)_{2}: \mathrm{d}=22.9 \AA\right)$ with the empirically calculated molecular volumes $\mathrm{V}_{\text {mol }}$. In that way, the molecular area $\mathrm{A}_{\mathrm{mol}}=\mathrm{V}_{\mathrm{mol}} / \mathrm{d}\left(=36-37 \AA^{2}\right)$ measures the 
lateral extension of lamellae and reflects the space requirement of the bulkiest molecular segment, here the self-associated dicyanovinylene-functionalized mesogens (the liquid aliphatic layers just spread to compensate the discrepancy with the minimum cross-section of chains: $24 \AA^{2}$ at 160 $\left.190^{\circ} \mathrm{C}\right)$.

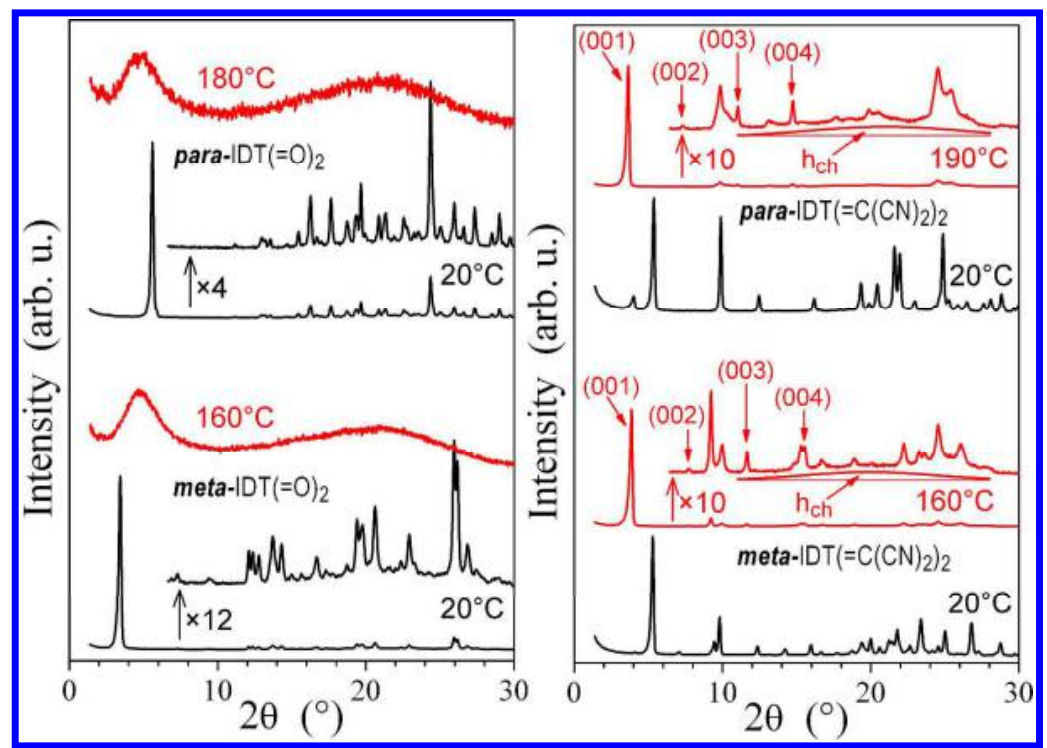

Figure 6: SWAXS patterns of IDT $(=\mathbf{O})_{2}$ and IDT $\left(=\mathbf{C}(\mathbf{C N})_{2}\right)_{2}$ regioisomers (left and right), at room temperature in the pristine state (bottom, black) and above the melting to the isotropic liquid (IDT $\left.(=\mathbf{O})_{2}\right)$ or to a three-dimensional lamellar mesophase $\left(\mathbf{I D T}\left(=\mathbf{C}(\mathbf{C N})_{2}\right)_{2}\right)$ (top, red); $h_{\mathrm{ch}}$ is the scattering signal from molten alkyl chains; the lamellar reflections series is identified by indexations $(00 l)$.

Finally, in this series of four structurally related compounds, the molecular organization turns out to be driven by the nature of the functionalization group borne by the mesogen. This an important finding for these two families of regioiomers. Thus, regioisomerism seems to have no significant effect on the nanosegregation and mesomorphism, and only limited influence on the crystalline state. More specifically, both para-derivatives show somewhat higher melting temperatures as their meta-analogues (same increase of $25-27^{\circ} \mathrm{C}$ ) and para-IDT( $\left.=\mathbf{O}\right)_{2}$ exhibits the richest crystalline polymorphism (three phases found on first heating, against a single one for the analogue (see Figures S4-S6 in the Supporting Information).

\section{Organic Field-Effect Transistors}

The potential of both IDT $\left(=\mathbf{C}(\mathbf{C N})_{2}\right)_{2}$ regioisomers has been investigated through the fabrication and electrical characterization of bottom-gate bottom-contact n-type channel OFETs in which they were used as active layer (see OFET structure in the Supporting Information Figure S18). Of particular interest, we also investigate the significant effect of the self-assembled monolayers (SAMs) of 4-(dimethylamino) benzenethiol (DABT) grafted on the gold drain and source electrodes on the OFET performance and stability (see device structure in the Supporting Information Figure S19). 
The fabrication process is described as follows: $150 \mathrm{~nm}$ thick aluminium layer was evaporated on the substrate (rigid glass or flexible polyethylene naphtalate) and patterned by conventional photolithography on a $5 \times 5 \mathrm{~cm}^{2}$ glass substrate. SU-8 2000.5 Photoresist from Microchem (see details on this photoresist in the Supporting Information) was then spin-coated in order to obtain a $400 \mathrm{~nm}$ thick layer. $50 \mathrm{~nm}$ thick gold layer was then thermally evaporated and patterned by photolithography.

For the devices on which the DABT was grafted, the DABT grafting was performed in drynitrogen glovebox by immersing the substrate in a $1.6 \mathrm{mg} / \mathrm{mL}(10 \mathrm{mmol} / \mathrm{L})$ acetone solution of $\mathrm{DABT}$ for $10 \mathrm{~min}$ at room temperature. The devices were then rinsed with acetone. Finally, the OSCs were deposited by evaporation under vacuum as a $40 \mathrm{~nm}$ thick layer. This bottom gate bottom contact structure, in which the OSC is evaporated during the last process step avoids any structural effect resulting from the next step. This will be discussed below.

The most important parameters, i.e. the mobility $\mu_{\mathrm{FE}}$, the threshold voltage $\mathrm{V}_{\mathrm{TH}}$, the subthreshold swing SS and the on/off values of the drain-source resistance $\mathrm{R}_{\mathrm{DS}}\left(\mathrm{I}_{\text {Don }} / \mathrm{I}_{\text {Doff }}\right)$ were extracted from the transfer characteristics in the linear and saturated regime of a series of at least 5 OFETs of different dimensions ( $\mathrm{W}=4000 \mu \mathrm{m}, \mathrm{L}=3$ to $50 \mu \mathrm{m}$ ), fabricated during the same process in order to get a more precise insight on the reproducibility of these values. The results presented in Table 2 are the average values and the best measured linear and saturated mobilities are presented between brackets. Electrical measurements were performed in a dry-nitrogen glovebox at room temperature, after a 1 hour annealing at $80^{\circ} \mathrm{C}$. The transfer characteristics of the best OFET with dimensions of $4000 \mu \mathrm{m} \times 20 \mu \mathrm{m}$ are presented in Figure 7 (complete output characteristics and additional transfer characteristics on PEN are available Figure S20-22 in supplementary data).

Table 2: Electrical properties of OFETs with and without DABT grafting on the drain/source electrodes. The numerical values represent the averages for at least 5 OFETs and the value between brackets is the maximum value obtained. The linear mobility was calculated from an $\mathrm{I}_{\mathrm{D}}-\mathrm{V}_{\mathrm{GS}}$ curve at $\mathrm{V}_{\mathrm{D}}=10 \mathrm{~V}$.

\begin{tabular}{|l|c|c|c|c|l|l|}
\hline \multicolumn{1}{|c|}{ OSC } & $\begin{array}{l}\mathrm{V}_{\mathrm{TH}} \\
(\mathrm{V})\end{array}$ & $\begin{array}{l}\mathrm{V}_{\mathrm{ON}} \\
(\mathrm{V})\end{array}$ & $\begin{array}{c}\mathrm{SS} \\
(\mathrm{V} / \mathrm{dec})\end{array}$ & $\mathrm{Id}_{\mathrm{on}} / \mathrm{Id}_{\mathrm{off}}$ & $\begin{array}{l}\text { Linear } \mu_{\mathrm{FE}} \\
\left(\mathrm{cm}^{2} \mathrm{~V}^{-1} \mathrm{~s}^{-1}\right)\end{array}$ & $\begin{array}{l}\text { Saturated } \mu_{\mathrm{FE}} \\
\left(\mathrm{cm}^{2} \mathrm{~V}^{-1} \mathrm{~s}^{-1}\right)\end{array}$ \\
\hline $\begin{array}{l}\text { para-IDT}\left(=\mathbf{C}(\mathbf{C N})_{2}\right)_{2} \\
\text { without DABT on glass }\end{array}$ & 36.8 & 5 & 1.6 & $2.3 \times 10^{7}$ & $5.9 \times 10^{-3}\left(7.4 \times 10^{-3}\right)$ & $1.2 \times 10^{-2}\left(1.6 \times 10^{-2}\right)$ \\
\hline $\begin{array}{l}\text { para-IDT(=C(CN) })_{2} \\
\text { without DABT on PEN }\end{array}$ & 31.4 & -3.8 & 2.5 & $1.1 \times 10^{7}$ & $1.2 \times 10^{-2}\left(2.5 \times 10^{-2}\right)$ & $3.8 \times 10^{-2}\left(7.1 \times 10^{-2}\right)$ \\
\hline $\begin{array}{l}\text { para-IDT(=C(CN) })_{2} \\
\text { with DABT on glass }\end{array}$ & 21.8 & -1.8 & 1.3 & $4.1 \times 10^{6}$ & $2.2 \times 10^{-2}\left(2.6 \times 10^{-2}\right)$ & $3.8 \times 10^{-2}\left(5.8 \times 10^{-2}\right)$ \\
\hline meta-IDT(=C(CN $\left.)_{2}\right)_{2}$ without DABT on glass & 48.6 & 5.1 & 2.0 & $1.1 \times 10^{7}$ & $2.7 \times 10^{-3}\left(3.8 \times 10^{-3}\right)$ & $7.2 \times 10^{-3}\left(1.0 \times 10^{-2}\right)$ \\
\hline meta-IDT(=C(CN) $)_{2}$ without DABT on PEN & 46.4 & 2.9 & 2.6 & $3.9 \times 10^{6}$ & $2.6 \times 10^{-3}\left(6.9 \times 10^{-3}\right)$ & $1.2 \times 10^{-2}\left(2.5 \times 10^{-2}\right)$ \\
\hline $\begin{array}{l}\left.\text { meta-IDT(=C(CN })_{2}\right)_{2} \\
\text { with DABT on glass }\end{array}$ & 51.3 & 0.5 & 1.2 & $1.4 \times 10^{7}$ & $9.6 \times 10^{-3}\left(1.3 \times 10^{-2}\right)$ & $1.8 \times 10^{-2}\left(2.5 \times 10^{-2}\right)$ \\
\hline
\end{tabular}



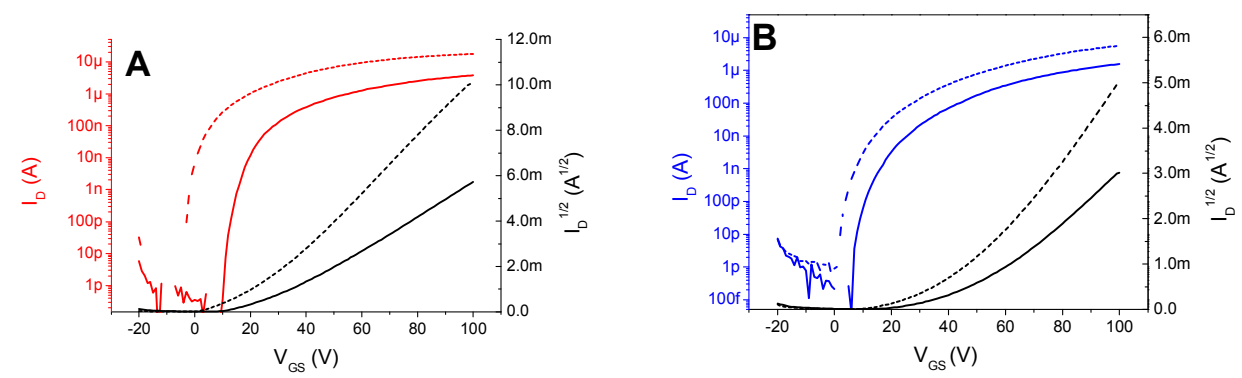

Figure 7: Transfer characteristics of OFETs with para-IDT $\left(=\mathbf{C}(\mathbf{C N})_{2}\right)_{2}(\mathrm{~A})$ and $\boldsymbol{m e t a}-\mathrm{IDT}\left(=\mathbf{C}(\mathbf{C N})_{2}\right)_{2}$ (B) on glass with (dotted line) and without DABT (straight line).

First, when comparing the performances of both compounds without DABT, it appears that paraIDT $\left(=\mathbf{C}(\mathbf{C N})_{2}\right)_{2}$ (Figure 7a, straight line) presents slightly better performances than those of its regioisomer meta-IDT $\left(=\mathbf{C}(\mathbf{C N})_{2}\right)_{2}$ (Figure $7 b$, straight line). Thus, the average linear field effect mobility $\left(5.9 \times 10^{-3} \mathrm{~cm}^{2} \mathrm{~V}^{-1} \mathrm{~s}^{-1}\right)$ and saturated mobility $\left(1.2 \times 10^{-2} \mathrm{~cm}^{2} \mathrm{~V}^{-1} \mathrm{~s}^{-1}\right)$ of paraIDT $\left(=\mathbf{C}(\mathbf{C N})_{2}\right)_{2}$ are about two times higher than those of meta-IDT $\left(=\mathbf{C}(\mathbf{C N})_{2}\right)_{\mathbf{2}}\left(2.7 \times 10^{-3} \mathrm{~cm}^{2} \mathrm{~V}^{-1}\right.$ $\mathrm{s}^{-1}$ and $7.2 \times 10^{-3} \mathrm{~cm}^{2} \mathrm{~V}^{-1} \mathrm{~s}^{-1}$ respectively). It should be noted that for para-IDT $\left(=\mathbf{C}(\mathbf{C N})_{2}\right)_{2}$, the best transistors exhibited high linear and saturated mobilities of $7.4 \times 10^{-3} \mathrm{~cm}^{2} \mathrm{~V}^{-1} \mathrm{~s}^{-1}$ and $1.6 \times 10^{-2} \mathrm{~cm}^{2} \mathrm{~V}^{-}$ ${ }^{1} \mathrm{~s}^{-1}$ respectively. Likewise, linear and saturated mobilities of $3.8 \times 10^{-3} \mathrm{~cm}^{2} \mathrm{~V}^{-1} \mathrm{~s}^{-1}$ and $1.0 \times 10^{-2} \mathrm{~cm}^{2}$ $\mathrm{V}^{-1} \mathrm{~s}^{-1}$ were obtained with $\boldsymbol{m e t a}$-IDT $\left(=\mathbf{C}(\mathbf{C N})_{2}\right)_{2}$. Different hypotheses can be made to explain the differences observed in the field-effect mobility. Indeed, it has been demonstrated that electrical conduction through an OSC can occur following three main mechanisms. The first is the band conduction mechanism, mainly observed in the case of mono-crystal OSCs, and corresponds to electrical conduction occurring in inorganic semi-conductor. In the case of well-organized organic materials (small molecule), Multiple Trap and Release (MTR) is the most commonly accepted mechanism. ${ }^{69}$ For amorphous semiconductor, carrier conduction is dominated by hopping mechanism. ${ }^{70}$ Obviously, electrical performances through MTR mechanism will be better than those with the hopping one. In this study, a better electrical conduction cannot be explained by a difference in the LUMO values as they are equivalent for each compound. The difference found in the electrical conduction could be rather related to the molecular organization. Indeed, a wellorganized OSC will limit the defect density, the carrier trapping and thus promote the MTR mechanism. In light of this explanation, para-IDT $\left(=\mathbf{C}(\mathbf{C N})_{2}\right)_{2}$ geometry seems to promote a better film packing than meta-IDT $\left(=\mathbf{C}(\mathbf{C N})_{2}\right)_{2}$ according to electrical performances.

Remarkably, both $\mathrm{I}_{\text {Don }} / \mathrm{I}_{\text {Doff }}$ ratio and subthreshold swing (SS) are very high and lye in the same range for both compounds $\left(\mathrm{I}_{\text {Don }} / \mathrm{I}_{\text {Doff }}=2.3 \times 10^{7}\right.$ vs $1.1 \times 10^{7}$ and SS=1.6 V/dec vs $2.0 \mathrm{~V} / \mathrm{dec}$ for para$\operatorname{IDT}\left(=\mathbf{C}(\mathbf{C N})_{2}\right)_{2}$ and $\boldsymbol{m e t a}$-IDT $\left(=\mathbf{C}(\mathbf{C N})_{2}\right)_{2}$ respectively $)$. It is well-known that electronic circuits as logic gates need to very efficiently switch from the "on state" to the "off state" in the smallest 
voltage window. These results are hence very encouraging to develop such electronic circuits in light of the very high and uniform calculated $\mathrm{I}_{\text {Don }} / \mathrm{I}_{\text {Doff }}$ ratio and low SS obtained. Finally, the $\mathrm{V}_{\mathrm{ON}}$ voltage, which corresponds to the potential at which the conduction canal is being formed was measured at c.a. $5 \mathrm{~V}$ for both compounds. This value appears to be low and highlights the potential of these OSCs for further applications.

It should be noted that structurally related pentaphenylene $\left(\mathbf{L P P}\left(=\mathbf{C}(\mathbf{C N})_{2}\right)_{2}\right)^{20}$ and terphenylene $\left(\boldsymbol{m e t a}-\mathbf{I F}\left(=\mathbf{C}(\mathbf{C N})_{2}\right)_{2}\right)^{21}$ previously reported in literature with similar device architecture display lower OFET performance, the main improvement being observed for the $\mathrm{I}_{\mathrm{ON}} / \mathrm{I}_{\mathrm{OFF}}$ ratio that remarkably increases from $2 / 6.3 \times 10^{5}$ for $\mathbf{L P P}\left(=\mathbf{C}(\mathbf{C N})_{2}\right)_{2} /$ meta $-\mathbf{I F}\left(=\mathbf{C}(\mathbf{C N})_{2}\right)_{2}$ to $2.3 / 1.1 \times 10^{7}$ for the para-/meta-IDT $\left(=\mathbf{C}(\mathbf{C N})_{2}\right)_{2}$. This shows the strong and highly beneficial influence of the incorporation of thiophene units within the main $\pi$-conjugated backbone compared to their phenyl analogues. $^{20-21}$

In literature, the OSC/insulator interface is often described to have a strong impact on the electrical properties of OFETs. ${ }^{71-72}$ It has been indeed shown that organic/organic materials used as OSC/insulator interface leads to a decrease of defects density compared to inorganic/organic interface. ${ }^{73}$ Moreover, SU-8 photoresist has already been used as insulator layer with very good results. $^{20-21,74}$ Considering the idea that organic/organic interface leads to a decrease of defect density compare to inorganic/organic interface, OSC organization in our devices cannot be the same at the interfaces between OSC/SU-8 (OSC/organic) and OSC/Gold (OSC/inorganic) leading to disorganized film on electrodes. In 2009, Kitamura et al have demonstrated that electrode functionalization with some benzenethiol derivatives such as DABT could increase the electrical performance due to a better OSC organization on drain and source electrodes. ${ }^{49}$ In order to test this hypothesis on the present devices, DABT was grafted on the gold electrodes prior to the evaporation of the OSC. This grafting successfully and strongly enhanced the performances of the present devices with an average linear mobility of $2.2 \times 10^{-2} \mathrm{~cm}^{2} \mathrm{~V}^{-1} \mathrm{~s}^{-1}$ (up to $2.6 \times 10^{-2} \mathrm{~cm}^{2} \mathrm{~V}^{-1} \mathrm{~s}^{-1}$ ) for para-IDT $\left(=\mathbf{C}(\mathbf{C N})_{2}\right)_{2}$ (Figure 7a, dotted line) and of $9.6 \times 10^{-3} \mathrm{~cm}^{2} \mathrm{~V}^{-1} \mathrm{~s}^{-1}$ (up to $1.3 \times 10^{-2} \mathrm{~cm}^{2} \mathrm{~V}^{-}$ ${ }^{1} \mathrm{~s}^{-1}$ ) for $\boldsymbol{m e t a}$-IDT $\left(=\mathbf{C}(\mathbf{C N})_{2}\right)_{2}$ (Figure $7 \mathrm{~b}$, dotted line). Interestingly, the saturated mobility was also impressively enhanced with an average value of $3.8 \times 10^{-2} \mathrm{~cm}^{2} \mathrm{~V}^{-1} \mathrm{~s}^{-1}$ obtained for paraIDT $\left(=\mathbf{C}(\mathbf{C N})_{2}\right)_{2}$ (up to $\left.5.8 \times 10^{-2} \mathrm{~cm}^{2} \mathrm{~V}^{-1} \mathrm{~s}^{-1}\right)$ and of $1.8 \times 10^{-2} \mathrm{~cm}^{2} \mathrm{~V}^{-1} \mathrm{~s}^{-1}$ for $\boldsymbol{m e t a}-\mathbf{I D T}\left(=\mathbf{C}(\mathbf{C N})_{2}\right)_{2}$ (up to $2.5 \times 10^{-2} \mathrm{~cm}^{2} \mathrm{~V}^{-1} \mathrm{~s}^{-1}$ ). An important feature needs to be stressed out. Indeed, saturated fieldeffect mobility for para-IDT $\left(=\mathbf{C}(\mathbf{C N})_{2}\right)_{2}$ has previously been obtained as high as $0.24 \mathrm{~cm}^{2} \mathrm{~V}^{-1} \mathrm{~s}^{-1}$ by Geng and coworkers ${ }^{50}$ in a bottom-gate-top-contact structure with substrate temperature of $80^{\circ} \mathrm{C}$ during semiconductor evaporation (with nevertheless a very high $\mathrm{V}_{\mathrm{TH}}$ of $33 \mathrm{~V}$ and a low $\mathrm{I}_{\mathrm{ON}} / \mathrm{I}_{\mathrm{OFF}}$ of $10^{4}$ ). Two hypotheses could be given to explain this difference. First, numerous studies 
1

have shown the high impact of the substrate temperature during the OSC deposition on field-effect mobility. Tian et al. obtained a maximum field-effect mobility for $\mathrm{T}_{\text {sub }}=80^{\circ} \mathrm{C}$ with lower values of $0.12 \mathrm{~cm}^{2} / \mathrm{V}$.s and $8.6 \times 10^{-2} \mathrm{~cm}^{2} / \mathrm{V}$.s for $\mathrm{T}_{\text {sub }}=60^{\circ} \mathrm{C}$ and $100^{\circ} \mathrm{C}$ respectively. The substrate temperature promotes the grain size of the molecule increasing the field-effect mobility until grain dissociation with the creation of void in the layer decreasing the electrical conduction and then the field-effect mobility of the device. In the present study, para-IDT $\left(=\mathrm{C}(\mathrm{CN})_{2}\right)_{2}$ and metaIDT $\left(=\mathbf{C}(\mathbf{C N})_{2}\right)_{2}$ have been deposited under vacuum at ambient temperature, which could hence explained the different mobilities obtained. Secondly, as previously explained, we achieve bottomgate-bottom-contact structure in order to compare these two molecules without any external effect. In fact, the OSCs have been deposited in the last step of the fabrication process (see more details in supplementary data).

According to previous studies, top-contact structure (such as that developed by Geng et al) ${ }^{50}$ is more adapted to extract channel/OSC mobility because of lower access resistance in the device. In the present study, extraction of field-effect mobilities takes account of access resistance and limits the field-effect mobility values. Considering these two hypotheses, the mobilities obtained herein are in the same range than those previously obtained for para-IDT $\left(=\mathbf{C}(\mathbf{C N})_{2}\right)_{2}$. However, it is important to note that the present OFETs using para-IDT $\left(=\mathbf{C}(\mathbf{C N})_{2}\right)_{2}$ possess very high $\mathrm{I}_{\text {Don }} / \mathrm{I}_{\text {Doff }}$ ratio $\left(2.3 \times 10^{7}\right)$, being around 1000 times higher than that previously reported $\left(10^{4}\right) .{ }^{50}$

The DABT grafting has not only a strong influence on mobilities but also on the $\mathrm{V}_{\mathrm{ON}}$ and on the SS. Thus, the SS was lowered for both compounds (from 1.6 to 1.3 for para-IDT $\left(=\mathbf{C}(\mathbf{C N})_{2}\right)_{2}$ and from 2.0 to 1.2 for $\left.\boldsymbol{m e t a - I D T}\left(=\mathbf{C}(\mathbf{C N})_{2}\right)_{2}\right)$ and the $\mathrm{V}_{\mathrm{ON}}$ voltage was impressively reduced from 5 to $-1.8 \mathrm{~V}$ for para-IDT $\left(=\mathbf{C}(\mathbf{C N})_{2}\right)_{2}$ and from 5.1 to $0.5 \mathrm{~V}$ for meta-IDT $\left(=\mathbf{C}(\mathbf{C N})_{2}\right)_{2}$. This variation can be linked to the improved conduction canal formation, due to a lesser number of defects within the OSC thanks to a better molecular organization. These promising values should allow these devices to be used in functional electronic circuits, which usually work at a potential of $5 \mathrm{~V}$.

Despite bottom-gate-bottom-contact structure with organic insulator and OSC presents higher access resistance, all the process steps are fully compatible with flexible substrate as PolyEthylene Naphtalate (PEN). This is an important feature in organic electronic technology. Thus, both para$\operatorname{IDT}\left(=\mathbf{C}(\mathbf{C N})_{2}\right)_{2}$ and meta-IDT $\left(=\mathbf{C}(\mathbf{C N})_{2}\right)_{2}$ have been successfully deposited at low temperature $\left(\mathrm{T}_{\max }=120^{\circ} \mathrm{C}\right)$ on flexible PEN substrate. In Table 2, performances of OFET have been extracted for glass substrate and PEN substrate (thickness $=25 \mu \mathrm{m}$ ) without DABT. Interestingly, both glass and PEN deposited OFETs display similar parameters showing the possibility to fully transfer the present structure on flexible substrate. More precisely, one can note an increase of both linear (X 
2) and saturated (X 3) field-effect mobility for flexible OFET with para-IDT $\left(=\mathbf{C}(\mathbf{C N})_{2}\right)_{2}$ whereas linear $\mu_{\mathrm{FE}}$ is the same with meta-IDT $\left(=\mathbf{C}(\mathbf{C N})_{2}\right)_{2}$ and saturated $\mu_{\mathrm{FE}}$ is multiplied by 1.7 from rigid to flexible devices. Saturated $\mu_{\mathrm{FE}}$ reach the high value of $7.1 \times 10^{-2} \mathrm{~cm}^{2} \mathrm{~V}^{-1} \mathrm{~s}^{-1}$ for paraIDT $\left(=\mathbf{C}(\mathbf{C N})_{2}\right)_{2}$ and of $2.5 \times 10^{-2} \mathrm{~cm}^{2} \mathrm{~V}^{-1} \mathrm{~s}^{-1}$ for meta-IDT $\left(=\mathbf{C}(\mathbf{C N})_{2}\right)_{2}$.

Electrical performances presented above such as field-effect mobility, threshold voltage or subthreshold slope are related to static characterization and are not relevant to understand electrical behaviour of OFETs in an electronic circuit. In future electronic devices, OFET will be used as either as switch or current source. In switch mode, off state and on state have to be very well differentiated $\left(\mathrm{I}_{\text {Don }} / \mathrm{I}_{\text {Doff }}\right)$, therefore frequency response and electrical stability under short polarization $(\mathrm{t}<1 \mathrm{~ms})$ have to be studied. As current source, the OFET will act as current supply for OLEDs, sensors or amplifiers. For these applications, current has to be constant under electrical polarization. A classical way to evaluate the electrical instability of an OFET is called gate-bias stress. It consists in stressing OFET with constant polarization for a while and then extract threshold voltage from transfer characteristics. Threshold voltage shift is then analysed to evaluate electrical stability of the device. Kippelen et al. ${ }^{26}$ have shown a simplified way to analyse electrical stability in OFET by measuring drain current decay under continuous polarization. This method has been applied to our devices over a period of 10 minutes. The results extracted from Figure 8 are summarized up in Table 3.

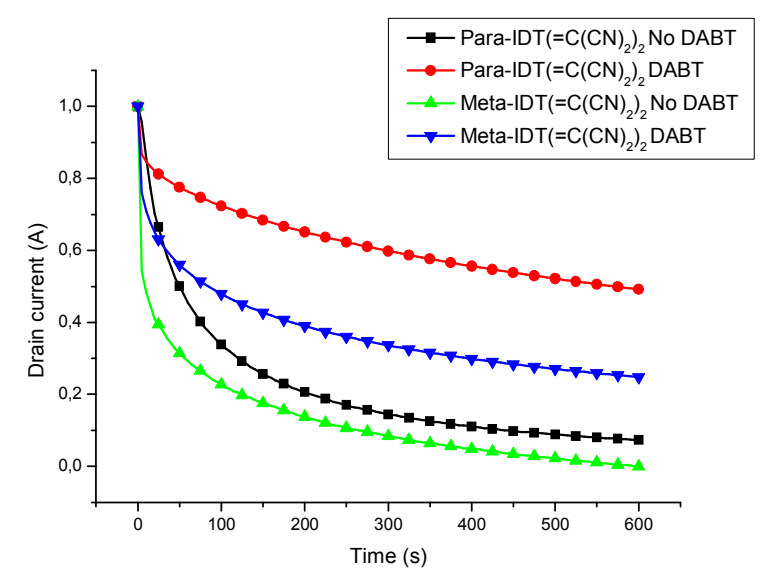

Figure 8. Measurement of drain-source channel on-current decay with time under continuous polarization using classical OFETs or DABT-modified OFETs.

Table 3: $\mathrm{Id}_{\text {final }} / \mathrm{Id}_{\mathrm{t}=0}$ after 10 min continuous polarization

\begin{tabular}{|c|c|c|c|c|}
\hline & $\begin{array}{c}\text { para-IDT }\left(=\mathbf{C}(\mathbf{C N})_{2}\right)_{2} \\
\text { without DABT }\end{array}$ & $\begin{array}{c}\text { para-IDT }\left(=\mathbf{C}(\mathbf{C N})_{2}\right)_{2} \\
\text { with DABT }\end{array}$ & $\begin{array}{c}\text { meta-IDT }\left(=\mathbf{C}(\mathbf{C N})_{2}\right)_{2} \\
\text { without DABT }\end{array}$ & $\begin{array}{c}\text { meta-IDT }\left(=\mathbf{C}(\mathbf{C N})_{2}\right)_{2} \\
\text { with DABT }\end{array}$ \\
\hline $\mathrm{Id}_{\text {final }} / \mathrm{Id}_{\mathrm{t}=0}(\%)$ & 7 & 49 & 0.8 & 24.8 \\
\hline
\end{tabular}

Without DABT, it appears that the current rapidly decreases for both isomers (Figure 8, black and green lines). However, one can note that the resulting $\mathrm{I}_{\mathrm{Dfinal}} / \mathrm{I}_{\mathrm{Dt}=0}$ ratio is ca 10 times higher for 
para-IDT $\left(=\mathbf{C}(\mathbf{C N})_{2}\right)_{2}$ than for meta-IDT $\left(=\mathbf{C}(\mathbf{C N})_{2}\right)_{2}(7 \%$ and $0.8 \%$ resp. $)$. As observed for the electrical performances, the intermolecular packing is responsible for a higher defect density into the meta-IDT $\left(=\mathbf{C}(\mathbf{C N})_{2}\right)_{2}$. Charge carrier trapping is then promoted and may explain the faster decrease of the drain current in meta-IDT $\left(=\mathbf{C}(\mathbf{C N})_{2}\right)_{2}$.

Numerous studies have demonstrated the strong impact of the insulator/OSC interface on OFETs electrical stability ${ }^{73,75}$. As shown in Table 3, the grafting of DABT on the drain-source electrodes has an impressive impact on the electrical stability of the present devices, showing the influence of the electrode/OSC interface on this matter. The enhancement of the ratio $\mathrm{Id}_{\text {final }} / \mathrm{Id}_{\mathrm{t}=0}$ observed for both compounds $\left(49 \%\right.$ and $24.8 \%$ for para-IDT $\left(=\mathbf{C}(\mathbf{C N})_{2}\right)_{2}$ and meta-IDT $\left(=\mathbf{C}(\mathbf{C N})_{2}\right)_{2}$ respectively) is then attributed to the decrease of the defect density at the gold/OSC interface.

Finally, it should be noted that the OSC/insulator interface is the same in the two different devices (with and without DABT) as the DABT was only grafted on the gold drain and source. This has been previously confirmed by one of us, ${ }^{74}$ by contact angle measurements demonstrating that no SU-8 surface energy modification occurs when SU-8 surface is exposed to a thiol derivative (octadecanethiol). Thus, the improvement of the electrical stability due to the DABT grafting is here remarkable. Previous works have already demonstrated that OSC/insulator interface has a high impact on electrical stability. ${ }^{73,75}$ In this study, as the electrical stability was strongly increased by the grafting of DABT (see above, Table 3 and Figure 8), we evidence that this stability is also dependent of electrode/OSC interface. It is then reasonable to conclude that electrical stability under constant polarization is dependent on the combination of both interfaces: electrode/OSC interface and insulator/OSC interface. We are currently working on the enhancement of this stability through a screening of the best combination of OSC, SAMs and insulator.

\section{Conclusion}

In summary, two members of a new family of OSC based on the dihydro-s-indaceno[1,2- $b: 7,6-b$ ']dithiophene core, namely meta-IDT $(=\mathbf{O})_{2}$ and meta $-\mathbf{I D T}\left(=\mathbf{C}(\mathbf{C N})_{2}\right)_{2}$, have been synthesised. Their main physicochemical properties have been studied in solution and in solid state, rationalized through theoretical calculations and compared to those of their corresponding regioisomers paraIDT $(=\mathbf{O})_{2}$ and para-IDT $\left(=\mathbf{C}(\mathbf{C N})_{2}\right)_{2}$. The new V-shaped central core of the meta-isomers leads to a decrease of the HOMO energy levels compare to the para-isomer derivatives, with nevertheless an identical LUMO energy level. This allows tuning the HOMO/LUMO gap. These molecules have been successfully incorporated as active layer in OFETs, either deposited on glass or on flexible PEN substrates. In both devices, para-IDT $\left(=\mathbf{C}(\mathbf{C N})_{2}\right)_{2}$ presents higher linear and saturated 
field-effect mobilities $\left(5.9 \times 10^{-3} / 1.2 \times 10^{-2} \mathrm{~cm}^{2} \mathrm{~V}^{-1} \mathrm{~s}^{-1}\right.$ on glass and $1.2 \times 10^{-2} / 3.8 \times 10^{-2} \mathrm{~cm}^{2} \mathrm{~V}^{-1} \mathrm{~s}^{-1}$ on PEN) than those of $\boldsymbol{m e t a}$-IDT $\left(=\mathbf{C}(\mathbf{C N})_{2}\right)_{2}\left(2.7 \times 10^{-3} / 7.2 \times 10^{-3} \mathrm{~cm}^{2} \mathrm{~V}^{-1} \mathrm{~s}^{-1}\right.$ on glass and $2.6 \times 10^{-}$ $3 / 1.2 \times 10^{-2} \mathrm{~cm}^{2} \mathrm{~V}^{-1} \mathrm{~s}^{-1}$ on PEN). The $\mathrm{I}_{\text {Don }} / \mathrm{I}_{\text {Doff }}$ ratio $\left(2.3 / 1.1 \times 10^{7}\right.$ on glass and $1.1 / 0.39 \times 10^{7}$ on PEN for the para-/meta-isomers) and subthreshold swing (1.6/2 V/dec on glass and 2.5/2.6 V/dec on PEN for the para-/meta-isomers) lye in the same range for both isomers and appears high and promising to further design electronic circuits. Another significant improvement of the device performances and of their electrical stabilities has been performed by modifying the gold electrodes by a SAMS of DABT. Such a modification remarkably improves the organization of the OSC on the electrode surface which leads to better charge transfer in the device and therefore significantly higher mobilities and stabilities (increase of the linear $\mu_{\mathrm{FE}}$ from $0.610^{-2}$ to $2.210^{-2} \mathrm{~cm}^{2}$ $\mathrm{V}^{-1} \mathrm{~s}^{-1}$ with para-IDT $\left(=\mathbf{C}(\mathbf{C N})_{2}\right)_{2}$ and from $2.7 \quad 10^{-3}$ to $9.610^{-3} \mathrm{~cm}^{2} \mathrm{~V}^{-1} \mathrm{~s}^{-1}$ with metaIDT $\left.\left(=\mathbf{C}(\mathbf{C N})_{2}\right)_{2}\right)$. Thus, despite slightly lower performance than those of the known and highly efficient para-IDT backbone, this work clearly shows the potential of the new meta-IDT core. Both para-IDT $\left(=\mathbf{C}(\mathrm{CN})_{2}\right)_{2}$ and meta-IDT $\left(=\mathbf{C}(\mathbf{C N})_{2}\right)_{2}$ based OFETs are currently investigated in circuits.

\section{ACKNOWLEDGMENTS}

We thanks the Region Bretagne and the Agence de l'Environnement et de la Maitrise de l'Energie (ADEME) for a studentship (JDP), Dr Bruno Laffite (ADEME), the University of Rennes 1 for financial support (Action Incitative 2013), the IETR for financial support, the C.R.M.P.O (Rennes) for mass analysis, the GENCI and the CINES for allocation of computing time under project c2015085032, and the ISA (Lyon) for TGA analysis. BD and BH thank the CNRS and Université de Strasbourg (UNISTRA) for support.

Supporting Information. Materials and methods, experimental details; synthesis, thermal properties, photophysical properties, theoretical modeling, OFET structures, preparation and characterizations, copy of NMR spectra.

\section{REFERENCES}

1. Lee, C. W.; Kim, O. Y.; Lee, J. Y. Organic Materials for Organic Electronic Devices. J. Ind. Eng. Chem. 2014, 20, 1198-1208.

2. Thirion, D.; Poriel, C.; Métivier, R.; Rault-Berthelot, J.; Barrière, F.; Jeannin, O. Violet-toBlue Tunable Emission of Aryl-Substituted Dispirofluorene-Indenofluorene Isomers by Conformationally-Controllable Intramolecular Excimer Formation. Chem. - Eur. J. 2011, 17, 10272-10287.

3. Poriel, C.; Rault-Berthelot, J.; Thirion, D.; Barrière, F.; Vignau, L. Blue Emitting $3 \pi-2$ Spiro Terfluorene-Indenofluorene Isomers: A Structure-Properties Relationship Study. Chem. Eur.J. 2011, 17, 14031-14046. 
4. Poriel, C.; Cocherel, N.; Rault-Berthelot, J.; Vignau, L.; Jeannin, O. Incorporation of Spiroxanthene Units in Blue-Emitting Oligophenylene Frameworks: A New Molecular Design for Oled Applications. Chem. - Eur. J. 2011, 17, 12631-12645.

5. Thirion, D.; Romain, M.; Rault-Berthelot, J.; Poriel, C. Intramolecular Excimer Emission as a Blue Light Source in Fluorescent Organic Light Emitting Diodes: A Promising Molecular Design. J. Mater. Chem. 2012, 22, 7149-7157.

6. $\quad$ Romain, M.; Tondelier, D.; Vanel, J.-C.; Geffroy, B.; Jeannin, O.; Rault-Berthelot, J.; Métivier, R.; Poriel, C. Dependence of the Properties of Dihydroindenofluorene Derivatives on Positional Isomerism: Influence of the Ring Bridging. Angew. Chem.Int.Ed. 2013, 52, 1414714151.

7. Cocherel, N.; Poriel, C.; Rault-Berthelot, J.; Barrière, F.; Audebrand, N.; Slawin, A. M. A.; Vignau, L. New $3 \pi-2$ spiro Ladder-Type Phenylene Materials: Synthesis, Physicochemical Properties and Applications in Oleds. Chem. - Eur.J. 2008, 14, 11328-11342.

8. Tyan, Y.-S. Organic Light-Emitting-Diode Lighting Overview J. Photon. Energy. 2011, 1, 011009.

9. Thiery, S.; Tondelier, D.; Declairieux, C.; Seo, G.; Geffroy, B.; Jeannin, O.; RaultBerthelot, J.; Métivier, R.; Poriel, C. 9,9'-Spirobifluorene and 4-Phenyl-9,9'-Spirobifluorene: Pure Hydrocarbon Small Molecules as Hosts for Green and Blue Pholeds. J. Mater. Chem. C 2014, 2, 4156-4166.

10. Thiery, S.; Declairieux, C.; Tondelier, D.; Seo, G.; Geffroy, B.; Jeannin, O.; Métivier, R.; Rault-Berthelot, J.; Poriel, C. 2-Substituted Vs 4-Substituted-9,9'-Spirobifluorene Host Materials for Green and Blue Phosphorescent Oleds: A Structure-Property Relationship Study. Tetrahedron 2014, 70, 6337-6351.

11. Romain, M.; Thiery, S.; Shirinskaya, A.; Declairieux, C.; Tondelier, D.; Geffroy, B.; Jeannin, O.; Rault-Berthelot, J.; Métivier, R.; Poriel, C. Ortho-, Meta-, and ParaDihydroindenofluorene Derivatives as Host Materials for Phosphorescent Oleds. Angew. Chem., Int. Ed. 2015, 54, 1176-1180.

12. Romain, M.; Tondelier, D.; Geffroy, B.; Shirinskaya, A.; Jeannin, O.; Rault-Berthelot, J.; Poriel, C. Spiro-Configured Phenyl Acridine Thioxanthene Dioxide as a Host for Efficient Pholeds. Chem. Commun. 2015, 51, 1313-1315.

13. Thiery, S.; Tondelier, D.; Declairieux, C.; Geffroy, B.; Jeannin, O.; Métivier, R.; RaultBerthelot, J.; Poriel, C. 4-Pyridyl-9,9'-Spirobifluorenes as Host Materials for Green and Sky-Blue Phosphorescent Oleds. J. Phys. Chem. C 2015, 119, 5790-5805.

14. Romain, M.; Tondelier, D.; Jeannin, O.; Geffroy, B.; Rault-Berthelot, J.; Poriel , C. Properties Modulation of Organic Semi-Conductors Based on a Donor-Spiro-Acceptor (D-Spiro-a) Molecular Design: New Host Materials for Efficient Sky-Blue Pholeds. J. Mater. Chem. C 2015, 3, 9701-9714.

15. Thiery, S.; Tondelier, D.; Geffroy, B.; Jacques, E.; Robin, M.; Métivier, R.; Jeannin, O.; Rault-Berthelot, J.; Poriel, C. Spirobifluorene-2,7-Dicarbazole-4'-Phosphine Oxide as Host for High-Performance Single-Layer Green Phosphorescent Oled Devices. Org. Lett. 2015, 17, 46824685 .

16. Thiery, S.; Tondelier, D.; Geffroy, B.; Jeannin, O.; Rault-Berthelot, J.; Poriel , C. Modulation of the Physicochemical Properties of Donor-Spiro-Acceptor Derivatives through Donor Unit Planarisation: Phenylacridine Versus Indoloacridine- New Hosts for Green and Blue Phosphorescent Organic Light-Emitting Diodes (Pholeds). Chem. - Eur. J. 2016, 22, 10136-10149. 17. Romain, M.; Quinton, C.; Tondelier, D.; Geffroy, B.; Jeannin, O.; Rault-Berthelot, J.; Poriel, C. Thioxanthene and Dioxothioxanthene Dihydroindeno[2,1-B]Fluorenes: Synthesis, Properties and Applications in Green and Sky Blue Phosphorescent Oleds. J. Mater. Chem. C 2016, 4, 1692-1703.

18. Tao, Y.; Yang, C.; Qin, J. Organic Host Materials for Phosphorescent Organic LightEmitting Diodes. Chem.Soc.Rev. 2011, 40, 2943-2970. 
19. Xiao, L.; Chen, Z.; Qu, B.; Luo, J.; Kong, S.; Gong, Q.; Kido, J. Recent Progresses on Materials for Electrophosphorescent Organic Light-Emitting Devices. Adv. Mater. 2011, 23, 926952.

20. Jacques, E.; Romain, M.; Yassin, A.; Bebiche, S.; Harnois, M.; Mohammed-Brahim, T.; Rault-Berthelot, J.; Poriel, C. An Electron Deficient Dicyanovinylene-Ladder-Type

Pentaphenylene Derivative for N-Type Organic Field Effect Transistors. J. Mater. Chem. C 2014, 2, 3292-3302.

21. Romain, M.; Chevrier, M.; Bebiche, S.; Mohammed-Brahim, T.; Rault-Berthelot, J.; Jacques, E.; Poriel, C. The Structure-Property Relationship Study of Electron-Deficient Dihydroindeno[2,1-B]Fluorene Derivatives for N-Type Organic Field Effect Transistors. J. Mater. Chem. C 2015, 3, 5742-5753.

22. Usta, H.; Facchetti, A.; Marks, T. J. N-Channel Semiconductor Materials Design for Organic Complementary Circuits Full Text. Acc.Chem.Res. 2011, 44, 501-510.

23. Wang, C.; Dong, H.; Hu, W.; Liu, Y.; Zhu, D. Semi-Conducting P-Conjugated Systems in Field-Effect Transistors: A Material Odyssey of Organic Electronics. Chem. Rev. 2012, 112, 22082267.

24. Mei, J.; Diao, Y.; Appleton, A. L.; Fang, L.; Bao, Z. Integrated Materials Design of Organic Semiconductors for Field-Effect Transistors. L.Am. Chem.Soc. 2013, 135 6724-6746.

25. Kaur, N.; Singh, M.; Pathak, D.; Wagner, T.; Nunzi, J. M. Organic Materials for Photovoltaic Applications: Review and Mechanism. Svnth. Met. 2014, 190, 20-26.

26. Zhang, X.-H.; Tiwari, S. P.; Kippelen, B. Pentacene Organic Field-Effect Transistors with Polymeric Dielectric Interfaces: Performance and Stability. Org. Elec. 2009, 10, 1133-1140.

27. Ortiz, R. P.; Facchetti, A.; Marks, T. J.; Casado, J.; Zgierski, M. Z.; Kozaki, M.; Hernández, V.; Navarrete, J. T. L. Ambipolar Organic Field-Effect Transistors from CrossConjugated Aromatic Quaterthiophenes; Comparisons with Quinoidal Parent Materials. $A d v$. Funct. Mater. 2009, 19, 386-394.

28. Gao, X.; Zhao, Z. High Mobility Organic Semiconductors for Field-Effect Transistors. Sci. China Chem. 2015, 58, 947-968.

29. Marshall, J. L.; Uchida, K.; Frederickson, C. K.; Schütt, C.; Zeidell, A. M.; Goetz, K. P.; Finn, T. W.; Jarolimek, K.; Zakharov, L. N.; Risko, C.; Herges, R.; Jurchescud, O. D.; Haley, M. M. Indacenodibenzothiophenes: Synthesis, Optoelectronic Properties and Materials Applications of Molecules with Strong Antiaromatic Character Chem. Sci. 2016, 7, 5547-5558.

30. Giri, G.; Verploegen, E.; Mannsfeld, S. C. B.; Atahan-Evrenk, S.; Kim, D. H.; Lee, S. Y.; Becerril, H. A.; Aspuru-Guzik, A.; Toney, M. F.; Bao, Z. Tuning Charge Transport in SolutionSheared Organic Semiconductors Using Lattice Strain. Nature 2011, 480, 504-508.

31. Kang, M. J.; Doi, I.; Mori, H.; Miyazaki, E.; Takimiya, K.; Ikeda, M.; Kuwabara, H. Alkylated Dinaphtho[2,3-B:2',3'-F]Thieno[3,2-B]Thiophenes (Cn-Dntts): Organic Semiconductors for High-Performance Thin-Film Transistors. Adv.Mater. 2011, 23, 1222-1225.

32. Mori, T.; Nishimura, T.; Yamamoto, T.; Doi, I.; Miyazaki, E.; Osaka, I.; Takimiya, K. Consecutive Thiophene-Annulation Approach to П-Extended Thienoacene-Based Organic Semiconductors with [1]Benzothieno[3,2-B][1]Benzothiophene (Btbt) Substructure. J. Am. Chem. Soc. 2013, 135 13900-13913.

33. Yuan, Y.; Giri, G.; Ayzner, A. L.; Zoombelt, A. P.; Mannsfeld, S. C. B.; Chen, J.; Nordlund, D.; Toney, M. F.; Huang, J.; Bao, Z. Ultra-High Mobility Transparent Organic Thin Film Transistors Grown by an Off-Centre Spin-Coating Method. Nat. Commun. 2013, 5, 3005. 34. Liu, Z.; Zhang, G.; Cai, Z.; Chen, X.; Luo, H.; Li, Y.; Wang, J.; Zhang, D. New Organic Semiconductors with Imide/Amide-Containing Molecular Systems Adv. Mater. 2014, 26, 69656977.

35. Zhang, C.; Zang, Y.; Gann, E.; McNeil, C. R.; Zhu, X.; Di, C.-a.; Zhu, D. TwoDimensional $\Pi$-Expanded Quinoidal Terthiophenes Terminated with Dicyanomethylenes as N- 
Type Semiconductors for High-Performance Organic Thin-Film Transistors. J. Am. Chem. Soc. 2014, 136, 16176-16184.

36. Zhang, F.; Hu, Y.; Schuettfort, T.; Di, C.-a.; Gao, X.; McNeill, C. R.; Thomsen, L.; Mannsfeld, S. C. B.; Yuan, W.; Sirringhaus, H.; Zhu, D. Critical Role of Alkyl Chain Branching of Organic Semiconductors in Enabling Solution-Processed N-Channel Organic Thin-Film Transistors with Mobility of up to $3.50 \mathrm{Cm}^{2} \mathrm{~V}^{-1} \mathrm{~S}^{-1}$. J.Am. Chem. Soc. 2013, 135, 2338-2349. 37. Zhang, C.; Zhu, X.-Z. The Impact of Regiochemistry of Conjugated Molecules on the Performance of Organic Electronic Devices. Chin. Chem. Lett. 2016, 27, 1357-1366.

38. Marshall, J. L.; O’Neal, N. J.; Zakharov, L. N.; Haley, M. M. Synthesis and Characterization of Two Unsymmetrical Indenofluorene Analogues: Benzo[5,6]-S-Indaceno[1,2B]Thiophene and Benzo[5,6]-S-Indaceno[2,1-B]Thiophene. J. Org. Chem. 2016, 81 3674-3680. 39. Barrière, F.; Poriel, C.; Rault-Berthelot, J. Experimental and Theoretical Insights into the Sequential Oxidations of $3 \pi-2$ spiro Molecules Derived from Oligophenylenes: A Comparative Study of 1,2-B-Dispirofluorene-Indenofluorene Versus 1,2- $B$-Dispirofluorene(Tert-Butyl) - $^{-}$ Indenofluorene. Electrochim. Acta 2013, 110, 735-740.

40. Poriel, C.; Rault-Berthelot, J.; Thirion, D. Modulation of the Electronic Properties of $3 \pi-$ 2spiro Compounds Derived from Bridged Oligophenylenes: A Structure-Property Relationship. $J$. Org. Chem. 2013, 78, 886-898.

41. Poriel, C.; Rault-Berthelot, J.; Barrière, F.; Slawin, A. M. Z. New Dispiro Compounds: Synthesis and Properties. Org. Lett. 2008, 10, 373-376.

42. Choi, H.; Jo, H.; Paek, S.; Koh, K.; Ko, H. M.; Lee, J. K.; Ko, J. Efficient HoleTransporting Materials with Triazole Core for High-Efficiency Perovskite Solar Cells. Chem. Asian J. 2016, 11, 548-554.

43. Cao, X.; Meng, L.; Li, Z.; Mao, Y.; Lan, H.; Chen, L.; Fan, Y.; Yi, T. Large Red-Shifted Fluorescent Emission Via Intermolecular П-П Stacking in 4-Ethynyl-1,8-Naphthalimide-Based Supramolecular Assemblies. Langmuir 2014, 30 11753-11760.

44. Lincker, F.; Attias, A.-J.; Mathevet, F.; Heinrich, B.; Donnio, B.; Fave, J.-L.; Rannou, P.; Demadrille, R. Influence of Polymorphism on Charge Transport Properties in Isomers of Fluorenone-Based Liquid Crystalline Semiconductors Chem.Commun. 2012, 48, 3209-3211.

45. Xia, D.; Marszalek, T.; Li, M.; Guo, X.; Baumgarten, M.; Pisula, W.; Müllen, K. SolutionProcessable N-Type Organic Semiconductors Based on Angular-Shaped 2-(12h-Dibenzofluoren12-Ylidene)Malononitrilediimide. Org.Lett. 2015, 17, 3074-3077.

46. Okamoto, T.; Mitsui, C.; Yamagishi, M.; Nakahara, K.; Soeda, J.; Hirose, Y.; Miwa, K.; Sato, H.; Yamano, A.; Matsushita, T.; Uemura, T.; Takeya, J. V-Shaped Organic Semiconductors with Solution Processability, High Mobility, and Thermal Durability. Adv.Mater. 2013, 25, 63926397.

47. Meng, Q.; Hu, W. Recent Progress of N-Type Organic Semiconducting Small Molecules for Organic Field-Effect Transistors. Phvs. Chem. Chem. Phvs. 2012, 14, 14152-14164.

48. Gao, X.; Hu, Y. Developments of N-Type Organic Semiconductors for Thin Films Transistors: A Viewpoint of Molecular Design. J. Mater. Chem. C 2014, 2, 3099-3117. 49. Kitamura, M.; Kuzumoto, Y.; Aomori, S.; Kamura, M.; Na, J. H.; Arakawa, Y. Threshold Voltage Control of Bottom-Contact $N$-Channel Organic Thin-Film Transistors Using Modified Drain/Source Electrodes Appl. Phvs. Lett. 2009, 94, 083310.

50. Tian, H.; Deng, Y.; Pan, F.; Huang, L.; Yan, D.; Geng, Y.; Wang, F. A Feasibly Synthesized Ladder-Type Conjugated Molecule as the Novel High Mobility N-Type Organic Semiconductor L.Mater. Chem. 2010, 20, 7998-8004.

51. Zhou, K.; Dong, H.; Zhang, H.-1.; Hu, W. High Performance N-Type and Ambipolar Small Organic Semiconductors for Organic Thin Film Transistors. Phys. Chem. Chem. Phys. 2014, 16, 22448-22457.

52. Kola, S.; Sinha, J.; Katz, H. E. Organic Transistors in the New Decade: Towards NChannel, Printed, and Stabilized Devices. J.Polvm.Sc. Part B. Pol.Phvs. 2012, 50, 1090-1120. 
53. Ozdemir, M.; Choi, D.; Kwon, G.; Zorlu, Y.; Kim, H.; Kim, M.-G.; Seo, S.; Sen, U.; Citir, M.; Kim, C.; Usta, H. Design, Synthesis, and Characterization of A, $\Omega$-Disubstituted Indeno[1,2B]Fluorene-6,12-Dione-Thiophene Molecular Semiconductors. Enhancement of Ambipolar Charge Transport through Synthetic Tailoring of Alkyl Substituents $\underline{\operatorname{RSC} A d v}$. 2016, 6, 212-226. 54. Bronstein, H.; Leem, D. S.; Hamilton, R.; Woebkenberg, P.; King, S.; Zhang, W.; Ashraf, R. S.; Heeney, M.; Anthopoulos, T. D.; de Mello, J.; McCulloch, I. Indacenodithiophene-CoBenzothiadiazole Copolymers for High Performance Solar Cells or Transistors Via Alkyl Chain Optimization. Macromolecules 2011, 44, 6649-6652.

55. Thirion, D.; Poriel, C.; Barrière, F.; Métivier, R.; Jeannin, O.; Rault-Berthelot, J. Tuning the Optical Properties of Aryl-Substituted Dispirofluorene-Indenofluorene Isomers through Intramolecular Excimer Formation. Org._Lett. 2009, 11, 4794-4797.

56. Romain, M.; Tondelier, D.; Geffroy, B.; Jeannin, O.; Jacques, E.; Rault-Berthelot, J.; Poriel, C. Donor/Acceptor Dihydroindeno[1,2-a]Fluorene and Dihydroindeno[2,1-B]Fluorene: Towards New Families of Organic Semiconductors. Chem. - Eur.J. 2015, 21, 9426-9439.

57. Poriel, C.; Rault-Berthelot, J.; Thiery, S.; Quinton, C.; Jeannin, O.; Biapo, U.; Tondelier, D.; Geffroy, B. 9h-Quinolino[3,2,1-K]Phenothiazine: A New Electron-Rich Fragment for Organic Electronics. Chem. - Eur.J. 2016, 22, 17930-17935.

58. Wang, Y.-K.; Sun, Q.; Wu, S.-F.; Yuan, Y.; Li, Q.; Jiang, Z.-Q.; Fung, M.-K.; Liao, L.-S. Thermally Activated Delayed Fluorescence Material as Host with Novel Spiro-Based Skeleton for High Power Efficiency and Low Roll-Off Blue and White Phosphorescent Devices. Adv. Funct. Mater. 2016, 26, 7929-7936.

59. Nielsen, C. B.; Voroshazi, E.; Holliday, S.; Cnops, K.; Rand, B. P.; McCulloch, I. Efficient Truxenone-Based Acceptors for Organic Photovoltaics J. Mater. Chem. A 2013, 1, 73-76.

60. Isoda, K.; Yasuda, T.; Kato, T. Dipole-Driven Self-Assembly of Redox-Active Mesogenic Tetracyanoanthraquinodimethanes. J. Mater. Chem. 2008, 18, 4522-4528.

61. Young, B. S.; Chase, D. T.; Marshall, J. L.; Vonnegut, C. L.; Zakharov, L. N.; Haley , M. M. Synthesis and Properties of Fully-Conjugated Indacenedithiophenes. Chem.Sci. 2014, 5, 10081014.

62. Jacob, J.; Sax, S.; Piok, T.; List, E. J. W.; Grimsdale, A. C.; Müllen, K. Ladder-Type Pentaphenylenes and Their Polymers : Efficient Blue-Light Emitters and Electron-Accepting Materials Via a Common Intermediate. J. Am. Chem. Soc. 2004, 126, 6987-6995.

63. Kowada, T.; Matsuyama, Y.; Ohe, K. Synthesis, Charactérization, and Photoluminescence of Thiophene-Containing Spiro Compounds. Synlett 2008, 12, 1902-1906.

64. Usta, H.; Facchetti, A.; Marks, T. J. Synthesis and Characterization of Electron-Deficient and Highly Soluble (Bis)Indenofluorene Building Blocks for N-Type Semiconducting Polymers. Org. Lett. 2008, 10, 1385-1388.

65. Usta, H.; Facchetti, A.; Marks, T. J. Air-Stable, Solution-Processable N-Channel and Ambipolar Semiconductors for Thin-Film Transistors Based on the Indenofluorenebis(Dicyanovinylene) Core. J.Am.Chem.Soc. 2008, 130, 8580-8581.

66. Tschierske, C. Non-Conventional Soft Matter. Annu. Rep. Prog. Chem., Sect. C: Phys. Chem. 2001, 97, 191-267.

67. Oikawa, K.; Monobe, H.; Takahashi, J.; Tsuchiya, K.; Heinrich, B.; Guillon, D.; Shimizu, Y. A Novel Calamitic Mesophase Semiconductor with the Fastest Mobility of Charged Carriers: 1,4-Di(5'-Octyl-2'-Thienyl)Benzene. Chem. Commun. 2005, 5337-5339

68. Mazur, L.; Castiglione, A.; Ocytko, K.; Kameche, F.; Macabies, R.; Ainsebaa, A.; Kreher, D.; Heinrich, B.; Donnio, B.; Sanaur, S.; Lacaze, E.; Fave, J.-L.; Matczyszyn, K.; Samoc, M.; Wu, J. W.; Attias, A.-J.; Ribierre, J.-C.; Mathevet, F. Charge Carrier Mobility Study of a Mesogenic Thienothiophene Derivative in Bulk and Thin Films. Org.Elec. 2014, 15, 943-953.

69. Horowitz, G. Organic Thin Film Transistors: From Theory to Real Devices. J. Materials Res. 2004, 19, 1946-1962 
70. Tessler, N.; Preezant, Y.; Rappaport, N.; Roichman, Y. Charge Transport in Disordered Organic Materials and Its Relevance to Thin-Film Devices: A Tutorial Review. Adv. Mater. 2009, 21, 2741-2761.

71. Ling, M.-M.; Erk, P.; Gomez, M.; Koenemann, M.; Locklin, J.; Bao, Z. Air-Stable NChannel Organic Semiconductors Based on Perylene Diimide Derivatives without Strong Electron Withdrawing Groups. Adv.Mater. 2007, 19, 1123-1127.

72. Zhang, X.-H.; Domercq, B.; Kippelen, B. High-Performance and Electrically Stable $\mathrm{C}_{60}$ Organic Field-Effect Transistors. Appl. Phvs. Lett. 2007, 91, 092114.

73. Hwang, D. K.; Fuentes-Hernandez, C.; Kim, J.; Potscavage Jr., W. J.; Kim, S.-J.; Kippelen, B. Top-Gate Organic Field-Effect Transistors with High Environmental and Operational Stability. Adv. Mater. 2011, 23, 1293-1298.

74. Robin, M.; Harnois, M.; Molard, Y.; Jacques, E. Improvement of N-Type Otft Electrical Stability by Gold Electrode Modification. Org. Elec. 2016, 39, 214-221.

75. Choi, H. H.; Lee, W. H.; Cho, K. Bias-Stress-Induced Charge Trapping at Polymer Chain Ends of Polymer Gate-Dielectrics in Organic Transistors. Adv. Funct. Mater. 2012, 22, 4833-4839.

\section{Table of Contents}

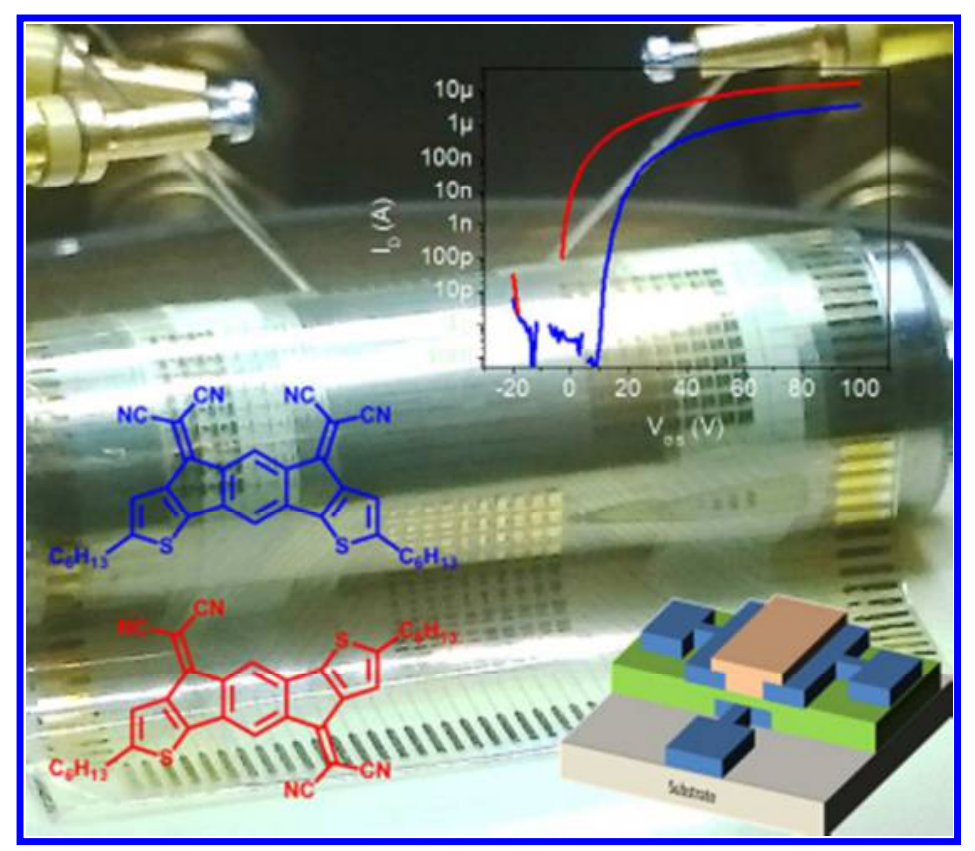

